\title{
Comparison of a global-climate model simulation to a cloud-system resolving model simulation for long-term thin stratocumulus clouds
}

\author{
S. S. Lee, J. E. Penner, and M. Wang \\ Department of Atmospheric, Oceanic, and Space Science, University of Michigan, Ann Arbor, MI, USA
}

Received: 16 March 2009 - Published in Atmos. Chem. Phys. Discuss.: 20 May 2009

Revised: 19 August 2009 - Accepted: 26 August 2009 - Published: 9 September 2009

\begin{abstract}
A case of thin, warm marine-boundary-layer (MBL) clouds is simulated by a cloud-system resolving model (CSRM) and is compared to the same case of clouds simulated by a general circulation model (GCM). In this study, the simulation by the CSRM adopts higher resolutions which are generally used in large-eddy simulations (LES) and more advanced microphysics as compared to those by the GCM, enabling the CSRM-simulation to act as a benchmark to assess the simulation by the GCM. Explicitly simulated interactions among the surface latent heat (LH) fluxes, buoyancy fluxes, and cloud-top entrainment lead to the deepening-warming decoupling and thereby the transition from stratiform clouds to cumulus clouds in the CSRM. However, in the simulation by the GCM, these interactions are not resolved and thus the transition to cumulus clouds is not simulated. This leads to substantial differences in liquid water content (LWC) and radiation between simulations by the CSRM and the GCM. When stratocumulus clouds are dominant prior to the transition to cumulus clouds, interactions between supersaturation and cloud droplet number concentration (CDNC) (controlling condensation) and those between rain evaporation and cloud-base instability (controlling cloud dynamics and thereby condensation) determine LWC and thus the radiation budget in the simulation by the CSRM. These interactions result in smaller condensation and thus smaller LWC and reflected solar radiation by clouds in the simulation by the CSRM than in the simulation by the GCM where these interactions are not resolved. The resolved interactions (associated with condensation and the transition to cumulus clouds) lead to better agreement between the CSRM-simulation and observation than that between the GCM-simulation and observation.
\end{abstract}

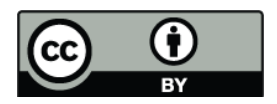

Correspondence to: S. S. Lee (seoungl@umich.edu)

\section{Introduction}

The formation of clouds in the marine boundary layer (MBL) is extremely important for both climate and climate sensitivity (Hartmann et al., 1992; Bony and Dufresne, 2005). These clouds and the associated convection in the MBL play an important role in the vertical structure of the MBL as well as air-sea fluxes of heat, moisture, and momentum (Tiedtke et al., 1988).

Aerosol concentrations have increased significantly as a result of industrialization. Increasing aerosols are generally considered to offset global warming by reflecting incoming solar radiation. Increasing aerosols are also known to decrease droplet size and thus increase cloud albedo (first aerosol indirect effect (AIE)) (Twomey, 1966, 1977). They may also suppress precipitation and, hence, alter LWC and lifetime (second AIE) (Albrecht, 1989). The AIE is uncertain, but is comparable to the radiative forcing associated with the increases in anthropogenic greenhouse gases (Ramaswamy et al., 2001; Forster et al., 2007).

Analyses from the International Satellite Cloud Climatology Project (ISCCP) reveal that low-level thin stratiform clouds (with the liquid-water path (LWP) $<\sim 50 \mathrm{~g} \mathrm{~m}^{-3}$ ) trapped in the MBL cover $28 \%$ of the globe. Hence, the interplay among these thin clouds, aerosols, and climate may have a substantial impact on climate changes and account for a large portion of the uncertainty associated with the AIE.

It is widely recognized that cloud parameterizations have been the cause of discrepancies in the prediction of climate change among general circulation models (GCMs) (Cubasch et al., 2001). Zhang et al. (2003) stated that two lines of complication arose in the parameterization of clouds in GCMs. The first is from the spatial and temporal subgridscale variability of the dynamic, thermodynamic, and hydrological variables within a GCM grid box. Most GCMs have relied on highly simplified parameterizations of subgridscale variables. The second is from microphysical processes

Published by Copernicus Publications on behalf of the European Geosciences Union. 
associated with aerosols (acting as cloud condensation nuclei, CCN; or ice nuclei, IN) and hydrometeors. Many of GCMs have adopted double-moment microphysics in recent years by employing nucleation schemes able to calculate the number concentration of nucleated droplets based on local aerosol properties (e.g. size distribution, chemical composition, and number concentration). This enables the prediction of cloud-particle size, an important parameter affecting the radiative properties of clouds as well as important microphysical processes such as the autoconversion (i.e. the conversion of cloud particles to precipitable hydrometeors through interactions among cloud particles), collection among different classes of hydrometeors, and sedimentation of hydrometeors. However, most of these GCMs still do not take into account the dependence of collection efficiencies (controlling the autoconversion and the collection processes) and the sedimentation velocities on the size distribution of hydrometeors explicitly. They generally rely on a threshold cloud-liquid-water mixing ratio for the autoconversion, a fixed collection efficiency for the collection processes, and a mass-weighted fall speed for the sedimentation, so that these representations do not consider the spectral information in the size distribution. This causes uncertainties in the simulation of the conversion of small cloud particles to precipitable hydrometeors and in the spatial redistribution of hydrometeors by the sedimentation. This in turn leads to uncertainties in the simulation of LWC and precipitation and thereby in the global radiation and hydrological budgets in GCMs.

This study aims to understand how the above-mentioned two lines of complication associated with cloud parameterizations lead to uncertainties in the simulation of microphysical and radiative properties of thin, warm MBL clouds (playing an important role in climate and in climate changes) in GCMs. To achieve this goal, this study compares the GCMsimulated MBL clouds to those clouds simulated by a cloudsystem resolving model (CSRM) for a selected region. As pointed out by Zhang et al. (2003), these two lines of complication associated with cloud parameterizations can be ideally dealt with by using high-resolution models and spectrally resolved descriptions of cloud particles and precipitable hydrometeors for autoconversion, collection, and sedimentation. Hence, by applying high-resolution grids and microphysical parameterizations that consider the spectral information in the CSRM used in this study, the cloud properties simulated by the CSRM can act as a benchmark to assess the uncertainties and associated mechanisms (inducing those uncertainties) in GCMs.

To draw climatic implications from the comparison between the GCM and CSRM simulations with better confidence, the comparison here is performed over the time scale associated with the approach to radiative-convective equilibrium, which is $\sim$ three weeks (Tompkins and Craig, 1998).

\section{CSRM}

For numerical experiments, the Goddard Cumulus Ensemble (GCE) model (Tao et al., 2003) is used as a CSRM, which is a three-dimensional nonhydrostatic compressible model. The detailed equations of the dynamical core of the GCE model are described by Tao and Simpson (1993) and Simpson and Tao (1993).

The subgrid-scale turbulence used in the GCE model is based on work by Klemp and Wilhelmson (1978) and Soong and Ogura (1980). In their approach, one prognostic equation is solved for the subgrid-scale kinetic energy, which is then used to specify the eddy coefficients. The effect of condensation on the generation of subgrid-scale kinetic energy is also incorporated into the model.

To represent microphysical processes, the GCE model adopts the double-moment bulk representation of Saleeby and Cotton (2004). The size distribution of hydrometeors obeys a generalized gamma distribution:

$n(D)=\frac{N_{t}}{\Gamma(v)}\left(\frac{D}{D_{n}}\right)^{v-1} \frac{1}{D_{n}} \exp \left(-\frac{D}{D_{n}}\right)$

where $D$ is the equivalent spherical diameter $(\mathrm{m}), n(D) d D$ the number concentration $\left(\mathrm{m}^{-3}\right)$ of particles in the size range $d D$, and $N_{t}$ the total number of particles $\left(\mathrm{m}^{-3}\right)$. Also, $v$ is the gamma distribution shape parameter (non-dimensional) and $D_{n}$ is the characteristic diameter of the distribution (m).

Full stochastic collection solutions for self-collection among cloud droplets and for rain drop collection of cloud droplets based on Feingold et al. (1988) are obtained using realistic collection kernels from Long (1974) and Hall (1980). Hence, this study does not constrain the system to a threshold mixing ratio and constant or average collection efficiencies. Following Walko et al. (1995), lookup tables are generated and used in each collection process. This enables fast and accurate solutions to the collection equations.

The philosophy of bin representation of collection is adopted for calculations of the drop sedimentation. The bin sedimentation is simulated by dividing the gamma distribution into discrete bins and then building lookup tables to calculate how much mass and number in a given grid cell falls into each cell beneath a given level in a given time step. Thus, this study does not rely on a mass-weighted fall speed for the sedimentation. 36 bins are used for the collection and the sedimentation. This is because Feingold et al. (1999) reported that the closest agreement between a full bin-resolving microphysics model in a large eddy simulation (LES) of marine stratocumulus cloud and the bulk microphysics representation was obtained when the collection and the sedimentation were simulated by emulating a full-bin model with 36 bins.

Cloud droplets are divided into small and large cloud droplets. Small and large cloud droplets range 2-40 $\mu \mathrm{m}$ and $40-80 \mu \mathrm{m}$ in diameter, respectively. The $40 \mu \mathrm{m}$ division between the two droplet modes is natural because it is well 
known that collection rates for droplets smaller than this size are very small, whereas droplets greater than this size participate in vigorous collision and coalescence. The large-clouddroplet mode is allowed to interact with all other species (i.e. with the small-cloud-droplet mode and rain for warm microphysics). The large-cloud-droplet mode plays a significant role in the collision-coalescence process by requiring droplets to grow at a slower rate as they pass from the smallcloud-droplet mode to rain, rather than being transferred directly from the small-cloud-droplet mode to rain.

All the cloud species here have their own terminal velocity. The terminal velocity of each species is expressed as power law relations (see Eq. (7) in Walko et al., 1995) based on the fall-speed formulations in Rogers and Yau (1989). A Lagrangian scheme is used to transport the mixing ratio and number concentration of each species from any given grid cell to a lower height in the vertical column, following Walko et al. (1995).

The cloud droplet nucleation parameterization of AbdulRazzak and Ghan $(2000,2002)$, which is based on Köhler theory, is used. This parameterization combines the treatment of multiple aerosol types and a sectional representation of size to deal with arbitrary aerosol mixing states and arbitrary aerosol size distributions. The bulk hygroscopicity parameter for each category of aerosol is the volume-weighted average of the parameters for each component taken from Ghan et al. (2001). In applying the Abdul-Razzak and Ghan parameterization, the size spectrum for each aerosol category is divided into 30 bins.

The equation for the change in mass of droplets from the vapor diffusion (i.e. condensation and evaporation) in this study, integrated over the size distribution, is as follows:

$\frac{d \bar{m}}{d t}=N_{d} 4 \pi \psi F_{\mathrm{Re}} S \rho_{\mathrm{vsh}}$

where $N_{d}$ is the cloud droplet number concentration (CDNC), $\psi$ the vapor diffusivity, and $\rho_{\mathrm{vsh}}$ the saturation water vapor mixing ratio. $S$ is the supersaturation, given by $\left(\frac{\rho_{\mathrm{va}}}{\rho_{\mathrm{vsh}}}-1\right)$ where $\rho_{\mathrm{va}}$ is water vapor mixing ratio. $F_{\mathrm{Re}}$ is the integrated product of the ventilation coefficient and droplet diameter which is given by

$$
F_{\mathrm{Re}}=\int_{0}^{\infty} D f_{\mathrm{Re}} f_{\mathrm{gam}}(D) d D
$$

where $D$ is the diameter of droplets, $f_{\mathrm{Re}}$ the ventilation coefficient, and $f_{\mathrm{gam}}(D)$ the distribution function, given by $\frac{1}{\Gamma(v)}\left(\frac{D}{D_{n}}\right)^{\nu-1} \frac{1}{D_{n}} \exp \left(-\frac{D}{D_{n}}\right) . \quad f_{\mathrm{Re}}$ is given by $\left[1.0+0.229\left(\frac{v_{t} D}{V_{k}}\right)^{0.5}\right] \eta$ where $v_{t}$ is the terminal velocity, $V_{k}$ the kinematic viscosity of air, and $\eta$ the shape parameter (Cotton et al., 1982). In the CSRM used here, the CDNC and the supersaturation are predicted and are fed into Eq. (2) for the calculations of the condensation and the evaporation.
The parameterizations developed by Chou and Suarez (1999) for shortwave radiation and by Chou and Kouvaris (1991), Chou et al. (1999), and Kratz et al. (1998) for longwave radiation have been implemented in the GCE model. The solar radiation scheme includes absorption due to water vapor, $\mathrm{CO}_{2}, \mathrm{O}_{3}$, and $\mathrm{O}_{2}$. Interactions among the gaseous absorption and scattering by clouds, molecules, and the surface are fully taken into account. Reflection and transmission of a cloud layer are computed using the $\delta$-Eddington approximation. Fluxes for a composite of layers are then computed using the two-stream adding approximation. In computing thermal infrared fluxes, the $\mathrm{k}$-distribution method with temperature and pressure scaling is used to compute the transmission function.

\section{GCM}

The GCM used here is the NCAR Community Atmospheric Model (CAM3) coupled with Integrated Massively Parallel Atmospheric Chemical Transport (IMPACT) aerosol model (CAM-UMICH) (Wang et al., 2009). The IMPACT aerosol model predicts aerosol mass for sea salt, dust, sulfate, black carbon and organic carbon (Liu et al., 2009). The original NCAR CAM3 model predicted both cloud-liquid-water mass and cloud-ice mass (Boville et al., 2006) and is updated with an additional prognostic equation for CDNC. In the coupled model, the dissipation of kinetic energy from the diffusion of momentum is calculated explicitly and included in the heating applied to the atmosphere.

The aerosol model component (IMPACT) solves prognostic equations for sulfur and related species: dimethylsulfide (DMS), sulfur dioxide $\left(\mathrm{SO}_{2}\right)$, sulfate aerosol $\left(\mathrm{SO}_{4}^{2-}\right)$, and hydrogen peroxide $\left(\mathrm{H}_{2} \mathrm{O}_{2}\right)$; aerosols from biomass burning black carbon (BC) and natural organic matter (OM), fossil fuel $\mathrm{BC}$ and $\mathrm{OM}$, natural $\mathrm{OM}$, aircraft $\mathrm{BC}$ (soot), mineral dust, and sea salt are also included. Sulfate aerosol is divided into three size bins with radii varying from $0.01-0.05 \mu \mathrm{m}$, $0.05-0.63 \mu \mathrm{m}$ and $0.63-1.26 \mu \mathrm{m}$, while mineral dust and sea salt are predicted in four bins with radii varying from $0.05-$ $0.63 \mu \mathrm{m}, 0.63-1.26 \mu \mathrm{m}, 1.26-2.5 \mu \mathrm{m}$, and $2.5-10 \mu \mathrm{m}$ (Liu et al., 2009). Carbonaceous aerosol (OM and BC) is currently represented by a single submicron size bin. Emissions of primary particles and precursor gases, gas-phase oxidation of precursor gases, aqueous-phase chemistry, rainout and washout, gravitational settling, and dry deposition are treated. The mass-only version of the IMPACT aerosol model driven by meteorological fields from the NASA Data Assimilation Office (DAO) participated in the AEROCOM (http://nansen.ipsl.jussieu.fr/AEROCOM/) phase A and B evaluations (Textor et al., 2006), where it has been extensively compared with in situ and remotely sensed data for different aerosol properties.

The physical parameterization used in the standard NCAR CAM3 is documented and evaluated by Boville et 
al. (2006) and Collins et al. (2006). The shallow stratiform clouds, which is the cloud type of interest to us here, are parameterized following the Rasch and Kristjánsson's (1998) treatment modified by Zhang et al. (2003). In this parameterization, the net stratiform condensation of cloud liquid water (condensation minus evaporation) is diagnosed based on environmental conditions such as temperature, water vapor, cloud-liquid-water mixing ratio, and cloud fraction. This is different from the condensation scheme used in the CSRM (described in Sect. 2) where the condensation is explicitly calculated based on predicted variables such as the supersaturation and the CDNC. The conversion of cloud liquid water to rain (through autoconversion and collection processes between cloud liquid water and rain) follows Boucher et al. (1995) and Tripoli and Cotton (1980), using a threshold mixing ratio and a constant collection efficiency with no consideration of the spectral hydrometeor information.

The standard CAM3 version has been updated with a prognostic equation for $\mathrm{CDNC}$, which replaces the prescribed CDNC used in the standard CAM3. This prognostic CDNC equation treats droplet source from aerosol particle activation and convective detrainment, and droplet sinks from evaporation, self-collection, and precipitation. The droplet activation is parameterized based on Köhler theory (Abdul-Razzak and Ghan, 2000, 2002), the same as that used in the CSRM. The droplet self-collection is based on the treatment of Beheng (1994), droplet depletion by precipitation and evaporation is assumed to be proportional to the depletion of LWC.

The coupled system is run with 26 vertical levels and a $2^{\circ} \times 2.5^{\circ}$ horizontal resolution. In the MBL, the vertical grid length is $\sim 300-600 \mathrm{~m}$. This system is run in MPMD (Multiple Processors Multiple Data) mode to exchange aerosol fields and meteorological fields at each advection time step of the IMPACT model. The finite volume dynamical core was chosen for the NCAR CAM. This version of the coupled model participated the AeroCOM indirect effect intercomparison project, where the simulated aerosol/cloud relationships have been extensively compared with satellite and field data.

\section{Integration design of the CAM-UMICH model}

A simulation is carried out with the present-day (PD) aerosol emissions using the coupled CAM-UMICH model. This simulation is referred to as the "GCM run", henceforth. The GCM run is integrated for 1 year after an initial spin-up of four months. The time step for CAM3 is $30 \mathrm{~min}$, and that for advection in IMPACT is $1 \mathrm{~h}$. The aerosol fields are assumed not to have any direct effect on the simulated meteorological fields.

Anthropogenic sulfur emissions are from Smith et al. (2001, 2004), and those for the year 2000 are used. Anthropogenic emissions of fossil fuel and biomass burning carbonaceous aerosols were from Ito and Penner (2005) a

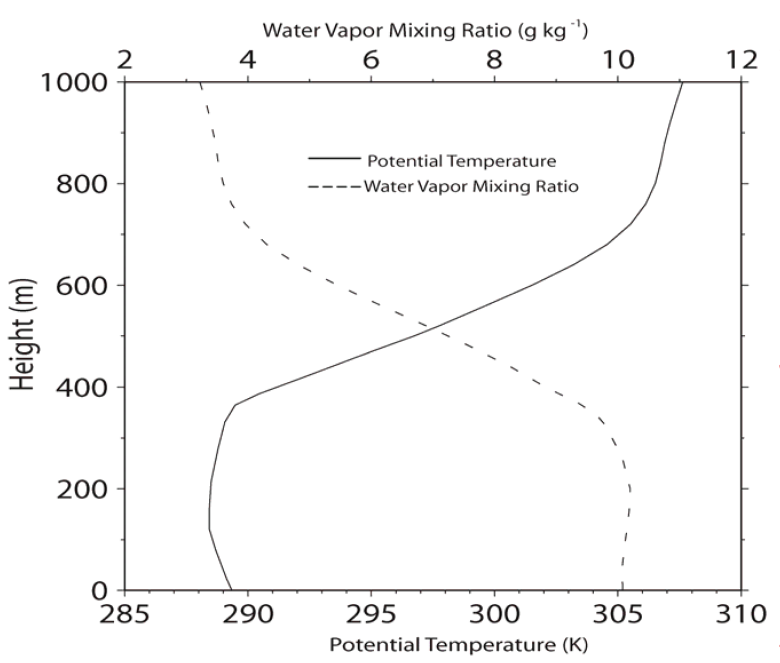

b

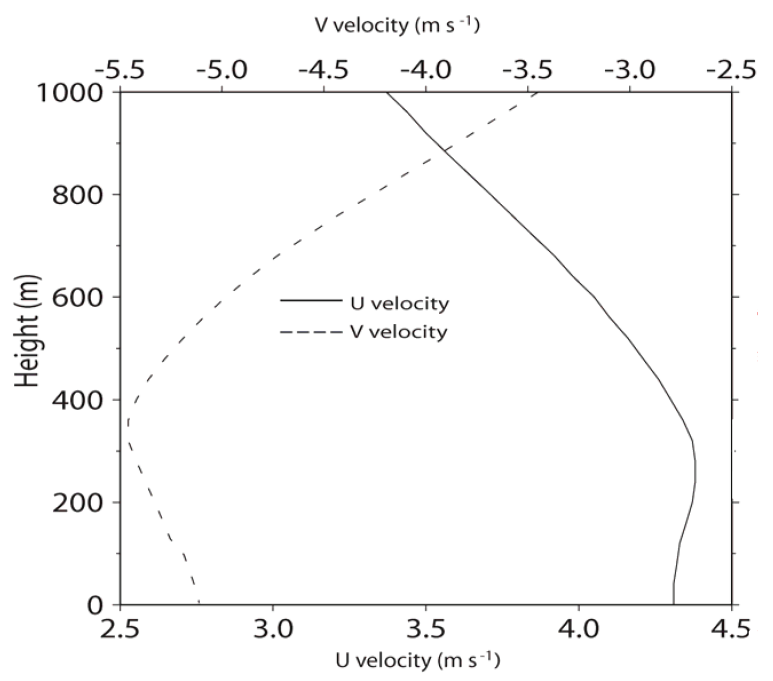

Fig. 1. Vertical profiles of (a) initial potential temperature and water vapor mixing ratio and $(\mathbf{b})$ initial horizontal wind $(u, v)$ velocity for the CSRM run.

but adjusted as discussed in Wang and Penner (2009). The year 2000 PD emissions include fossil fuel BC and OM, and biomass burning $\mathrm{BC}$ and $\mathrm{OM}$. Natural emissions included volcanic $\mathrm{SO}_{2}$ from Andres and Kasgnoc (1998), marine dimethylsulfide (DMS) from Kettle and Andreae (2000), OM from vegetation from Penner et al. (2001), and mineral dust provided by Ginoux (personal communication, 2004) for the year 1998 based on the algorithm of Ginoux et al. (2001). Sea salt emissions are calculated online in the coupled CAM-UMICH model using the method defined in Gong et al. (1997). 
a
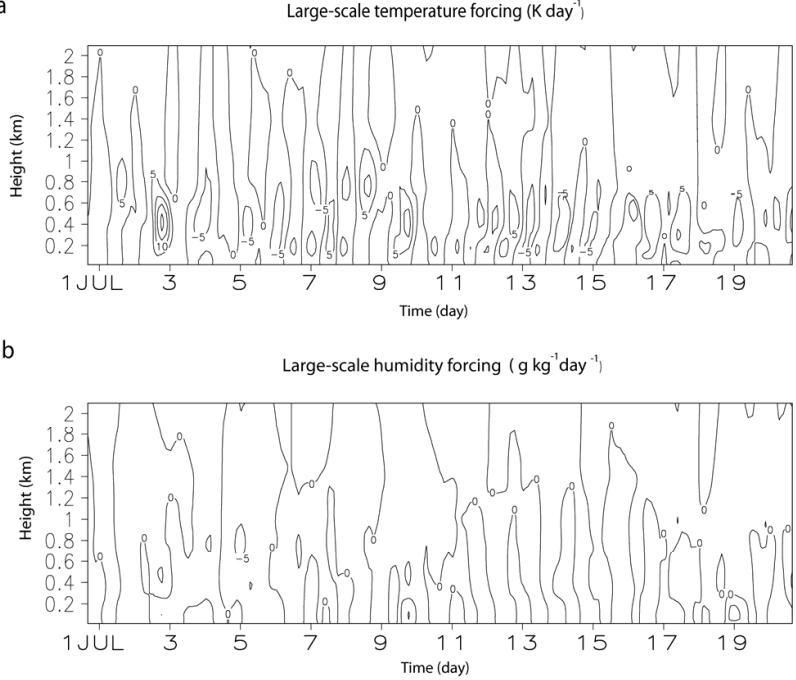

Fig. 2. Time-height cross section of (a) potential temperature large-scale forcing $\left(\mathrm{K} \mathrm{day}^{-1}\right)$ and (b) humidity large-scale forcing $\left(\mathrm{g} \mathrm{kg}^{-1} \mathrm{day}^{-1}\right)$ for the CSRM run. Contours start at 0 and the contour interval is 5 .

\section{Case descriptions and integration design of the CSRM}

MBL stratocumulus clouds develop at $\left(30^{\circ} \mathrm{N}, 120^{\circ} \mathrm{W}\right)$ off the coast of the western Mexico from $\sim 30$ June to $\sim 20$ July in the GCM run. These clouds are selected for a comparison between the GCM and CSRM simulations.

For the CSRM simulation (referred to as the "CSRM run" henceforth), initial conditions, large-scale forcings of humidity and temperature, and surface fluxes are extracted from the GCM run from 16:00 LST (local solar time) on 30 June to 16:00 LST on 20 July at $\left(30^{\circ} \mathrm{N}, 120^{\circ} \mathrm{W}\right)$. These extracted environmental conditions are imposed on the CSRM run so that the CSRM run can be performed under the same environmental conditions as those in the GCM run. The largescale forcings of humidity and temperature and surface fluxes are extracted every $3 \mathrm{~h}$. The 3-hourly data are applied to the CSRM at every time step by interpolation. The time step of the CSRM run is $0.5 \mathrm{~s}$. The horizontally averaged wind from the GCE model is nudged toward the interpolated wind field from the GCM run at every time step with a relaxation time of one hour, following Xu et al. (2002). The large-scale terms are approximated to be uniform over the model domain and they are defined to be functions of height and time only, following Krueger et al. (1999). This method of modeling cloud systems was used for a CSRM comparison study by $\mathrm{Xu}$ et al. (2002). The details of the procedure for applying large-scale forcings and surface fluxes are described in Donner et al. (1999) and are similar to the method proposed by Grabowski et al. (1996).
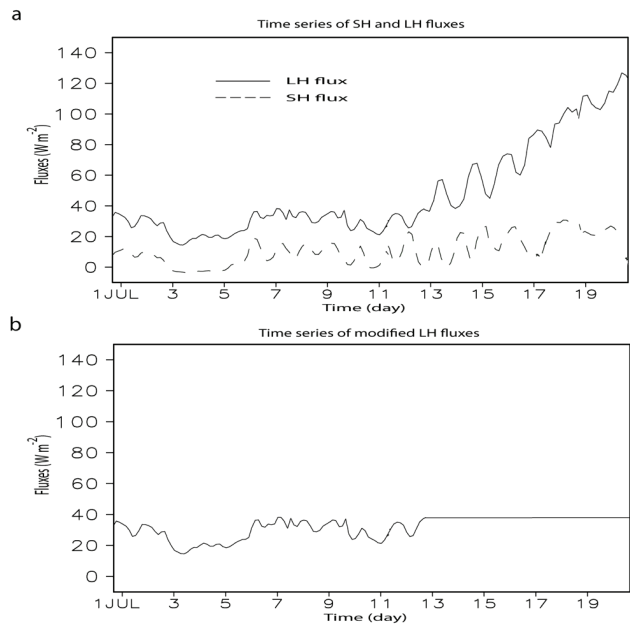

Fig. 3. Time series of surface sensible $(\mathrm{SH})$ and latent $(\mathrm{LH})$ heat fluxes $\left(\mathrm{W} \mathrm{m}^{-2}\right.$ ) (a) for the CSRM run and (b) time series of $\mathrm{LH}$ surface fluxes for the CSRM-LH run.

Vertical profiles of initial specific humidity, potential temperature, and horizontal wind velocity applied to the CSRM run are shown in Fig. 1 and large-scale forcings and surface fluxes imposed on the CSRM are depicted in Figs. 2 and 3a, respectively. The profiles of humidity and potential temperature indicate that the initial inversion layer is formed around $400 \mathrm{~m}$. Below the inversion layer, $u$ (wind in the east-west direction) and $v$ (wind in the north-south direction) velocities do not vary much as the humidity and the potential temperature. The plus and minus indicate eastward (northward) and westward (southward) wind direction for the $u(v)$ velocities. The large-scale forcings show the diurnal variation. The sensible heat (SH) fluxes do not vary significantly, whereas the latent heat $(\mathrm{LH})$ fluxes increase significantly after around 00:00 LST 13 July. Figure 3b depicts the latent heat fluxes used in a supplementary simulation which will be discussed in more detail in Sect. 6.3.

The CSRM run is performed in a 3-D framework. A uniform grid length of $50 \mathrm{~m}$ is used in the horizontal domain and the vertical grid length is uniformly $20 \mathrm{~m}$ below $3 \mathrm{~km}$ and then stretches to $480 \mathrm{~m}$ near the model top. Periodic boundary conditions are set at the horizontal boundaries.

It is ideal to set the size of the model domain in the CSRM run to be the same as that of one grid box of the GCM run for better confidence in the comparison between the CSRM run and the GCM run. However, the horizontal length of the grid box in the GCM run is on the order of $100 \mathrm{~km}$. For the 20-day simulation (adopting the resolutions above) with a model domain with a horizontal length around $100 \mathrm{~km}$ and with a vertical length covering the troposphere, enormous central processing unit (CPU) hours on a supercomputer system would be needed. Our calculations show that around $6.5 \times 10^{7} \mathrm{CPU}$ hours would be needed for the simulations if 


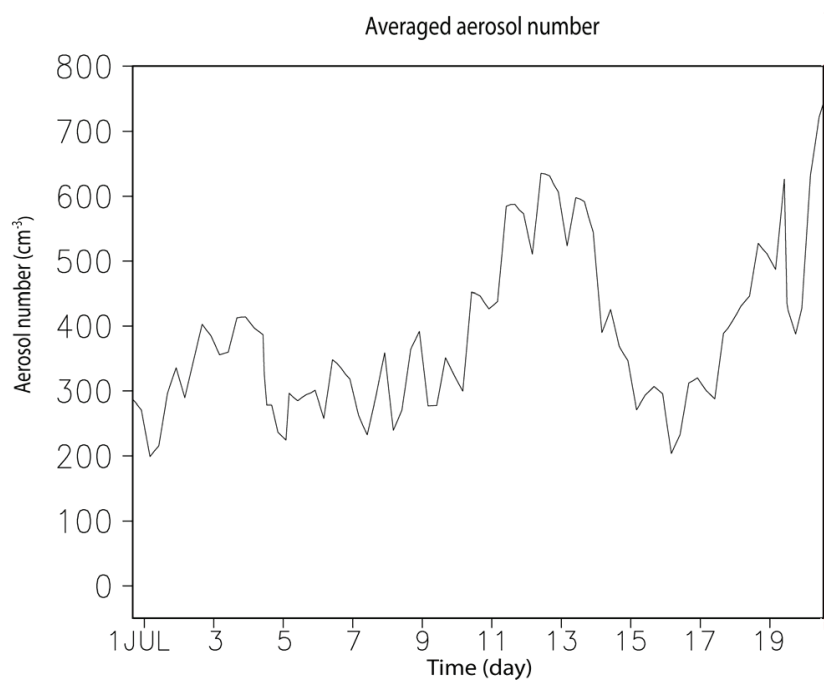

Fig. 4. Time series of background aerosol number concentration $\left(\mathrm{cm}^{-3}\right)$ averaged over the MBL in the CSRM run.

we used 1000 parallel CPUs for such a computation. These CPU hours are $\sim 2$ times larger than total hours assigned to the entire set of climate groups in the National Energy Research Scientific Computing (NERSC) center (whose supercomputer system is used for this study) in the year 2008. Also, it should be pointed out that the total wall-clock time needed for this simulation is $\sim 7$ years despite the use of 1000 CPUs. Hence, a compromise is needed by finding a domain size which is large enough to simulate the MBL clouds reasonably yet small enough to enable us to perform simulations within the given computer resources and within a reasonable well-clock time range.

Various field experiments performed in both clear and cloudy boundary layers have shown that generally a significant amount of variance in large-scale disturbances (whose spatial scale is comparable to the size of the GCM grid box) is present at the mesoscale spatial scale for quantities such as moisture, temperature, or the horizontal wind components (e.g. Nicholls and LeMone, 1980; Rothermel and Agee, 1980; Nucciarone and Young, 1991; Davis et al., 1996; Jonker et al., 1997; Young, 1987; Durand et al., 2000). de Roode et al. (2004) reported that the spatial scale of mesoscale fluctuations was $\sim 10-20 \mathrm{~km}$ in general. Based on this, the horizontal domain length is set to $12 \mathrm{~km}$ in both the east-west and north-south directions in this study to capture the mesoscale structures whose properties can be assumed to represent those of the large-scale disturbances reasonably well. The vertical domain length is $20 \mathrm{~km}$ to cover troposphere and the lower stratosphere. To make a consistency in radiation between the CSRM and the GCM above $20 \mathrm{~km}$ (the GCM vertical domain extends to the pressure level of $3 \mathrm{hPa}$, corresponding to $\sim 40 \mathrm{~km}$ ), additional layers representing atmospheric conditions above $20 \mathrm{~km}$ are applied only to radiation scheme in the CSRM run as described in Tao et al. (2003).

Xiping et al. (2007) compared a 20-day cloud simulation of a CSRM to observations by applying observed initial conditions, large-scale forcings, and surface fluxes to the CSRM. Similarly, this study compares the CSRM run to the GCM run by applying environmental data (produced by the GCM) to the CSRM adopted here. These GCM-produced data are 3 hourly (the same as the observed data in Xiping et al. (2007)) and collected with a similar vertical resolution to that in observed data in Xiping et al. (2007). This enables a similar comparison of the CSRM run to the GCM run to the comparison of the CSRM simulation to observations in Xiping et al. (2007). The GCM run in this study is analogous to the observations in Xiping et al. (2007), since it provides the environmental conditions to the simulation by the CSRM here. However, in Xiping et al. (2007), observations acted as a benchmark to evaluate the performance of the CSRM, whereas, in this study, the CSRM run is intended to act as a benchmark to evaluate the GCM run by applying the higher resolution and advanced microphysics to the CSRM used here.

Background aerosol data for the CSRM run are provided by the coupled CAM-UMICH model from 16:00 LST on 30 June to $16: 00 \mathrm{LST}$ on $20 \mathrm{July}$ at $\left(30^{\circ} \mathrm{N}, 120^{\circ} \mathrm{W}\right)$. Hence, the CSRM run is under the same background aerosol conditions as those in the GCM run. The predicted aerosol mass of each aerosol species by the GCM run is obtained every $6 \mathrm{~h}$. These mass data are interpolated into every time step to update the background aerosols in the CSRM run. The aerosol mass is approximated to be uniform over the model horizontal domain and is defined to be a function of height and time only.

Aerosol number concentration is calculated from the mass profiles using parameters (mode radius, standard deviation, and partitioning of aerosol number among modes) described in Chuang et al. (1997) for sulfate aerosols and Liu et al. (2005) for non-sulfate aerosols (e.g. fossil fuel BC/OM, biomass $\mathrm{BC} / \mathrm{OM}$, sea salt, and dust) as in the GCM runs. Here, bi- or tri-modal log-normal size distribution is assumed for aerosols and the number of aerosols in each size bin of the distribution is determined using these parameters and assumed aerosol particle density for each species. In the MBL, background aerosol number is nearly constant and only varies vertically within $10 \%$ of its value at the surface. The time series of the vertically averaged total background aerosol number over the MBL in the CSRM run is shown in Fig. 4. Generally, the aerosol number varies between 200 and $700 \mathrm{~cm}^{-3}$, indicating that these aerosols correspond to typical clean continental aerosols (Whitby, 1978).

The aerosol is predicted within clouds and reset to the background value at all levels outside cloud. Within clouds, aerosols are advected, diffused, and depleted by nucleation of 
Table 1. Summary of simulations.

\begin{tabular}{|c|c|c|c|c|c|c|}
\hline Simulation & Model & Location & Period & Aerosol & Cloud & $\begin{array}{l}\text { Surface LH } \\
\text { flux }\end{array}$ \\
\hline GCM run & $\begin{array}{l}\text { IMPACT- } \\
\text { CAM } \\
\text { Model }\end{array}$ & Globe & $\begin{array}{l}\text { One year } \\
\text { after the } \\
\text { spin-up } \\
\text { time of } \\
\text { four months }\end{array}$ & $\begin{array}{l}\text { Globally } \\
\text { predicted }\end{array}$ & $\begin{array}{l}\text { Globally } \\
\text { predicted }\end{array}$ & $\begin{array}{l}\text { Globally } \\
\text { predicted }\end{array}$ \\
\hline $\begin{array}{l}\text { GCM- } \\
\text { RAD run }\end{array}$ & $\begin{array}{l}\text { GCM } \\
\text { radiation }\end{array}$ & $\begin{array}{l}\left(30^{\circ} \mathrm{N},\right. \\
\left.120^{\circ} \mathrm{W}\right)\end{array}$ & $\begin{array}{l}\text { One time } \\
\text { step from } \\
\text { 00:00 LST } \\
\text { 1 July }\end{array}$ & Not applied & Imposed & $\begin{array}{l}\text { Surface LH } \\
\text { flux at }(30 \circ \mathrm{N}, \\
\left.120^{\circ} \mathrm{W}\right)\end{array}$ \\
\hline CSRM run & $\begin{array}{l}\text { GCE } \\
\text { model }\end{array}$ & $\begin{array}{l}\left(30^{\circ} \mathrm{N}\right. \\
\left.120^{\circ} \mathrm{W}\right)\end{array}$ & $\begin{array}{l}30 \text { June to } \\
20 \text { July }\end{array}$ & $\begin{array}{l}\text { Aerosols at } \\
\left(30^{\circ} \mathrm{N},\right. \\
\left.120^{\circ} \mathrm{W}\right)\end{array}$ & Predicted & $\begin{array}{l}\text { Surface } \mathrm{LH} \\
\text { flux at }\left(30^{\circ} \mathrm{N} \text {, }\right. \\
\left.120^{\circ} \mathrm{W}\right)\end{array}$ \\
\hline $\begin{array}{l}\text { CSRM- } \\
\text { CLR run }\end{array}$ & $\begin{array}{l}\text { GCE } \\
\text { model }\end{array}$ & $\begin{array}{l}\left(40^{\circ} \mathrm{N}\right. \\
\left.123^{\circ} \mathrm{W}\right)\end{array}$ & $\begin{array}{l}30 \text { June to } \\
20 \text { July }\end{array}$ & $\begin{array}{l}\text { Aerosols at } \\
\left(40^{\circ} \mathrm{N},\right. \\
\left.123^{\circ} \mathrm{W}\right)\end{array}$ & $\begin{array}{l}\text { Predicted/ } \\
\text { Not formed }\end{array}$ & $\begin{array}{l}\text { Surface LH } \\
\text { flux at }\left(40^{\circ} \mathrm{N},\right. \\
\left.123^{\circ} \mathrm{W}\right)\end{array}$ \\
\hline $\begin{array}{l}\text { CSRM- } \\
\text { RAD run }\end{array}$ & $\begin{array}{l}\text { GCE } \\
\text { radiation }\end{array}$ & $\begin{array}{l}\left(30^{\circ} \mathrm{N}\right. \\
\left.120^{\circ} \mathrm{W}\right)\end{array}$ & $\begin{array}{l}\text { One time } \\
\text { step from } \\
\text { 00:00 LST } \\
1 \text { July }\end{array}$ & Not applied & Imposed & $\begin{array}{l}\text { Surface } \mathrm{LH} \\
\text { flux at }\left(30^{\circ} \mathrm{N} \text {, }\right. \\
\left.120^{\circ} \mathrm{W}\right)\end{array}$ \\
\hline $\begin{array}{l}\text { CSRM- } \\
\text { LH run }\end{array}$ & $\begin{array}{l}\text { GCE } \\
\text { model }\end{array}$ & $\begin{array}{l}\left(30^{\circ} \mathrm{N}\right. \\
\left.120^{\circ} \mathrm{W}\right)\end{array}$ & $\begin{array}{l}30 \text { June to } \\
20 \text { July }\end{array}$ & $\begin{array}{l}\text { Aerosols at } \\
\left(30^{\circ} \mathrm{N},\right. \\
\left.120^{\circ} \mathrm{W}\right)\end{array}$ & Predicted & $\begin{array}{l}\text { Same as in } \\
\text { the CSRM } \\
\text { run but with } \\
\text { a fixed value } \\
\text { after 00:00 LST } \\
13 \text { July }\end{array}$ \\
\hline $\begin{array}{l}\mathrm{CSRM} \times 2 \\
\text { run }\end{array}$ & $\begin{array}{l}\text { GCE } \\
\text { model }\end{array}$ & $\begin{array}{l}\left(30^{\circ} \mathrm{N},\right. \\
\left.120^{\circ} \mathrm{W}\right)\end{array}$ & $\begin{array}{l}30 \text { June to } \\
20 \text { July }\end{array}$ & $\begin{array}{l}\text { Same as in } \\
\text { the CSRM run } \\
\text { but increased } \\
\text { by a factor of } 2\end{array}$ & Predicted & $\begin{array}{l}\text { Surface } \mathrm{LH} \\
\text { flux at }\left(30^{\circ} \mathrm{N},\right. \\
\left.120^{\circ} \mathrm{W}\right)\end{array}$ \\
\hline
\end{tabular}

droplets (nucleation scavenging). Initially, the aerosol number is set equal to its background value everywhere.

Table 1 summarizes simulations in this study. In addition to the GCM run and the CSRM run, Table 1 shows that supplementary simulations are performed. They will be described in more detail in the following sections.

This study focuses on aerosol effects on the nucleation of cloud particles and thereby cloud microphysical and radiative properties and, thus, does not take into account aerosol direct effects on radiation. In other words, only aerosol impacts on cloud-particle properties after its activation are taken into account for both the GCM run and the CSRM run.

\section{Results}

\subsection{Clear-sky case}

There are differences in schemes other than those for cloud schemes between the CSRM run and the GCM run (see Collins et al., 2006a; Liu et al., 2005; and Tao et al., 2003, for those differences). Hence, differences in results between the CSRM run and the GCM run may be caused not only by differences in cloud schemes but also by schemes for other physical and dynamical processes. Hence, comparisons between the CSRM run and the GCM run for the selected case would not be able to isolate the effect of cloud schemes on the simulations. Since this study focuses on the effects of different cloud parameterizations between the CSRM run and the GCM run on simulated clouds, we first show that the results from the comparison here are robust to different schemes other than those for cloud processes. 

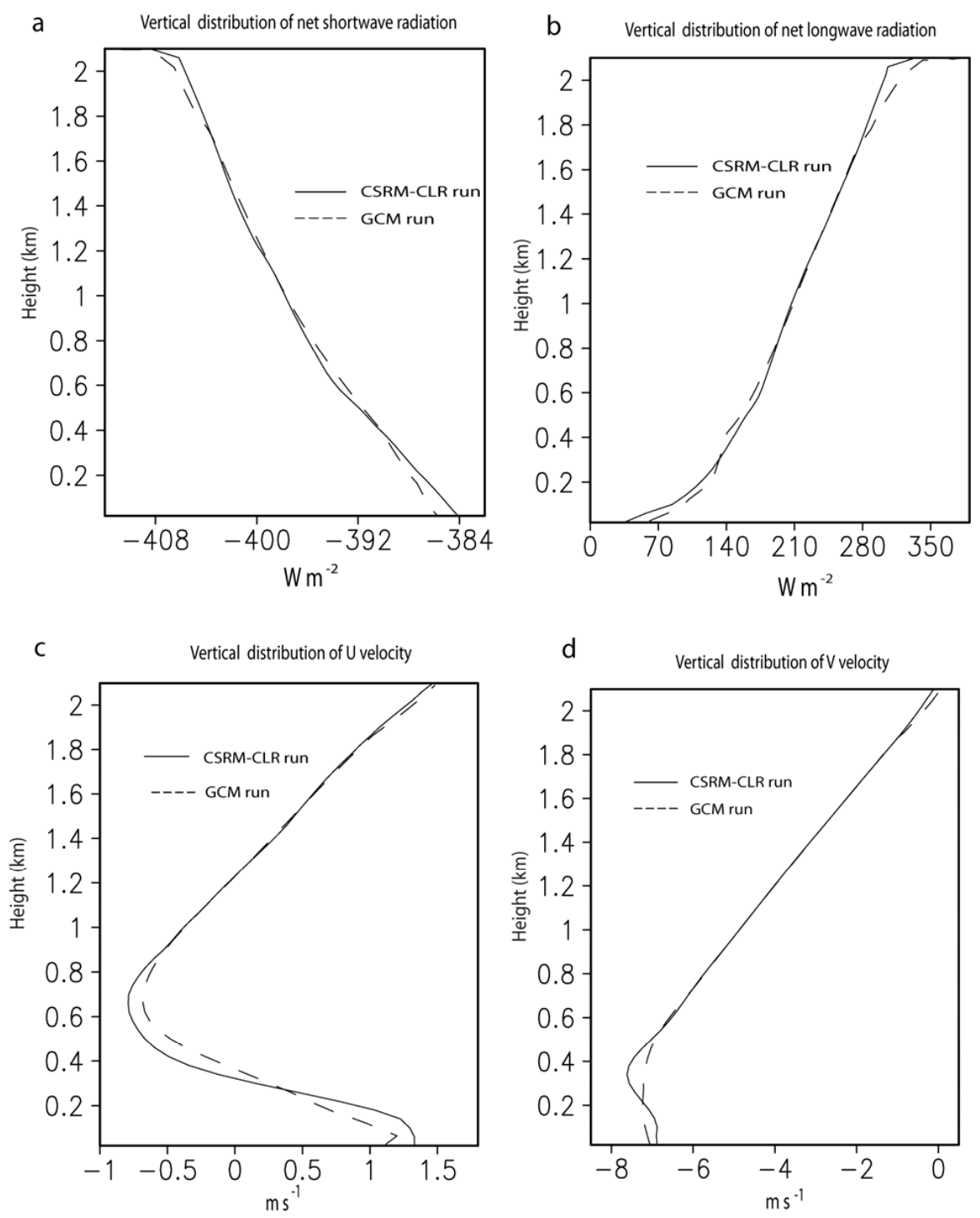

Fig. 5. Vertical distribution of the time- and area-averaged (a) net shortwave fluxes, (b) net longwave fluxes, (c) $u$ wind velocity, (d) $v$ wind velocity, (e) potential temperature, (f) pressure, (g) water-vapor mixing ratio, and (h) aerosol number concentration for the CSRM-CLR run and the GCM run at $\left(40^{\circ} \mathrm{N}, 123^{\circ} \mathrm{W}\right)$. In (a) and (b), plus and minus indicate upward and downward fluxes, respectively.

To show this robustness, a CSRM simulation for a clearsky case is simulated. Henceforth, this CSRM simulation is referred to as the CSRM-CLR run. A region at $\left(40^{\circ} \mathrm{N}\right.$, $123^{\circ} \mathrm{W}$ ) where no clouds are formed over a 20-day period (16:00 LST on 30 June to 16:00 LST on 20 July) in the GCM run is selected for the CSRM-CLR run. The CSRMCLR run is identical to the CSRM run but the initial conditions, the large-scale forcings, and the surface fluxes produced by the GCM run at $\left(40^{\circ} \mathrm{N}, 123^{\circ} \mathrm{W}\right)$ are used. Comparing the CSRM-CLR run to the GCM run in the absence of clouds enables a test of the robustness to the differences in schemes other than schemes for clouds, since those schemes for clouds are not activated in the clear-sky case.
Figure 5 shows the vertical distribution of the timeand area-averaged radiation fluxes (minus and plus indicate downward and upward fluxes), horizontal winds, temperature, pressure, water-vapor mixing ratio, and aerosol number concentration for the CSRM-CLR run and the GCM run. Figure 6 shows the time series of domain-averaged values of those variables over the lowest $2 \mathrm{~km}$ for the CSRM-CLR run and the GCM run; they are averaged over the lowest $2 \mathrm{~km}$, since this study focuses on low-level warm stratocumulus clouds. In this study, the GCM results are interpolated into the CSRM grids and time levels. Figures 5 and 6 show that differences in simulated fields between the CSRM-CLR run and the GCM run are within $\sim 10 \%$ of each other. This 

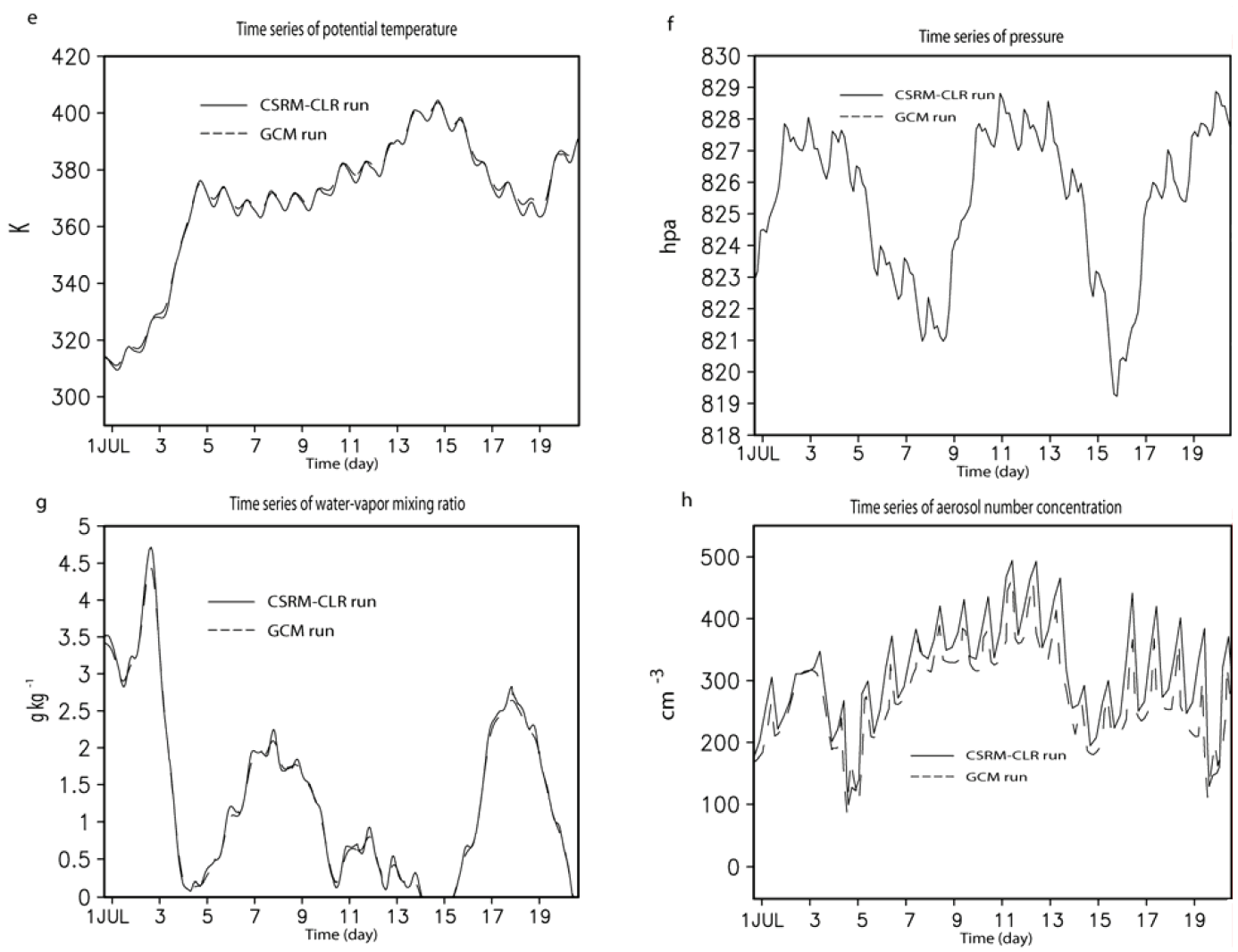

Fig. 6. Time series of domain-averaged (over the lowest $2 \mathrm{~km}$ ) (a) net shortwave fluxes, (b) net longwave fluxes, (c) $u$ wind velocity, (d) $v$ wind velocity, (e) potential temperature, (f) pressure, (g) water-vapor mixing ratio, and (h) aerosol number concentration for the CSRM-CLR run and the GCM run at $\left(40^{\circ} \mathrm{N}, 123^{\circ} \mathrm{W}\right)$. In (a) and (b), minus and plus indicate downward and upward fluxes, respectively.

demonstrates that we are able to assume that the results of this study are not significantly sensitive to the schemes not associated with clouds. This in turn enables us to assume that differences in the results for a cloud case between the CSRM run and the GCM run are mostly attributable to differences in cloud schemes.

In the case of radiation schemes, the prescription of parameters for the radiative properties of cloud particles is different between the CSRM and the GCM adopted here. Hence, it is necessary to show that radiation schemes do not show significant differences in the responses to identical clouds, though radiation schemes do not show significant differences in the clear-sky case. If there are insignificant differences in the radiation for identical clouds, the different prescriptions of radiative parameters within clouds can be assumed to not contribute to differences between the CSRM run and the GCM run. In other words, it is the different cloud properties (e.g. LWC and effective size) due to different cloud schemes (but not the different prescription of radiative parameters) that contribute to differences in radiation, if the radiation schemes respond similarly to identical clouds. To test the responses of the radiation schemes to identical clouds, idealized simulations are carried out.
For these simulations, the radiation schemes are separated from the CSRM and the GCM and the initial meteorological conditions of the CSRM run and the GCM run at $\left(30^{\circ} \mathrm{N}\right.$, $120^{\circ} \mathrm{W}$ ) are fed into those radiation schemes. These simulations are performed within a 1-D framework for just one time step, which is $0.5 \mathrm{~s}$. The model domain has only the vertical domain whose depth is $20 \mathrm{~km}$. For these radiation schemes, a cloud layer, with a homogeneous cloud-liquid-water mixing ratio and effective size throughout the cloud layer, between $200 \mathrm{~m}$ and $400 \mathrm{~m}$ is imposed. The vertical extent of cloud layer is based on stratocumulus clouds which are generally simulated in a layer between $200 \mathrm{~m}$ and $400 \mathrm{~m}$ in the CSRM run and $\mathrm{GCM}$ run at $\left(30^{\circ} \mathrm{N}, 120^{\circ} \mathrm{W}\right)$; these simulated clouds will be described in more detail in the following sections. Simulated stratocumulus clouds generally have cloud-liquidwater mixing ratio between 0.01 and $0.6 \mathrm{~g} \mathrm{~kg}^{-1}$ and the effective radius of the simulated cloud droplets is generally between 3 and $18 \mu \mathrm{m}$ in the CSRM run and the GCM run. Based on this, cloud-liquid-water mixing ratios of $0.01,0.05$, $0.2,0.4$, and $0.6 \mathrm{~g} \mathrm{~kg}^{-1}$ and the effective radii of 5 and $15 \mathrm{um}$ are selected and applied to the imposed clouds. From this selection, 10 combinations of the cloud-liquid-water mixing ratio and the effective radius are imposed as shown in 
Table 2. Time- and area-averaged net shortwave radiation flux (SW) and longwave radiation flux (LW) at $20 \mathrm{~km}$ (TOA) and base (SFC) of the atmosphere for the CSRM-RAD run and the GCM-RAD run.

\begin{tabular}{|c|c|c|c|c|c|c|c|c|c|}
\hline \multicolumn{10}{|c|}{$\begin{array}{l}\text { Shortwave flux (SW) and longwave flux (LW) } \\
\text { at } 20 \mathrm{~km}(\mathrm{TOA}) \text { and base (SFC) of the model in the CSRM-RAD run and the GCM-RAD run }\left(\mathrm{W} \mathrm{m}^{-2}\right)\end{array}$} \\
\hline \multirow{2}{*}{$\begin{array}{r}\text { Effective } \\
\text { radius }(\mu \mathrm{m})\end{array}$} & \multirow{2}{*}{$\begin{array}{l}\text { Cloud-liquid- } \\
\text { water mixing } \\
\text { ratio }\left(\mathrm{g} \mathrm{kg}^{-1}\right)\end{array}$} & \multicolumn{2}{|c|}{ TOA SW } & \multicolumn{2}{|c|}{ TOA LW } & \multicolumn{2}{|c|}{ SFC SW } & \multicolumn{2}{|c|}{ SFC LW } \\
\hline & & $\begin{array}{r}\text { CSRM } \\
\text { radiation }\end{array}$ & $\begin{array}{r}\mathrm{GCM} \\
\text { radiation }\end{array}$ & $\begin{array}{r}\text { CSRM } \\
\text { radiation }\end{array}$ & $\begin{array}{r}\mathrm{GCM} \\
\text { radiation }\end{array}$ & $\begin{array}{r}\text { CSRM } \\
\text { radiation }\end{array}$ & $\begin{array}{r}\mathrm{GCM} \\
\text { radiation }\end{array}$ & $\begin{array}{r}\text { CSRM } \\
\text { radiation }\end{array}$ & $\begin{array}{r}\mathrm{GCM} \\
\text { radiation }\end{array}$ \\
\hline 5 & 0.01 & -707.7 & -680.7 & 314.1 & 325.2 & -582.9 & -562.3 & 98.1 & 103.1 \\
\hline 5 & 0.05 & -641.7 & -610.2 & 312.6 & 319.6 & -513.0 & -500.2 & 65.4 & 69.2 \\
\hline 5 & 0.2 & -492.6 & -480.5 & 310.4 & 316.1 & -354.2 & -342.1 & 26.8 & 29.1 \\
\hline 5 & 0.4 & -396.6 & -387.5 & 309.5 & 315.9 & -251.2 & -245.2 & 18.3 & 20.3 \\
\hline 5 & 0.6 & -344.4 & -340.1 & 309.0 & 315.3 & -194.8 & -190.3 & 15.2 & 17.1 \\
\hline 15 & 0.01 & -711.7 & -691.3 & 314.2 & 325.1 & -585.9 & -565.6 & 99.4 & 104.2 \\
\hline 15 & 0.05 & -657.8 & -620.5 & 312.8 & 319.2 & -525.0 & -512.1 & 70.4 & 75.6 \\
\hline 15 & 0.2 & -526.3 & -510.3 & 310.2 & 316.8 & -378.4 & -367.1 & 28.9 & 30.2 \\
\hline 15 & 0.4 & -434.2 & -425.2 & 309.5 & 315.6 & -275.9 & -269.5 & 18.6 & 20.5 \\
\hline 15 & 0.6 & -382.2 & -375.1 & 309.0 & 315.2 & -216.5 & -211.7 & 16.3 & 18.0 \\
\hline
\end{tabular}

a Time-height cross section of cloud-liquid-water mixing ratio $\left(\mathrm{g} \mathrm{kg}^{-1}\right)$ (CSRM run)

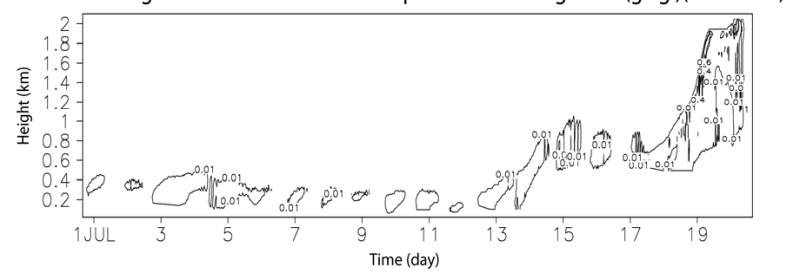

b Time-height cross section of cloud-liquid-water mixing ratio ( $\left.\mathrm{kg}^{-1}\right)(\mathrm{GCM}$ run)

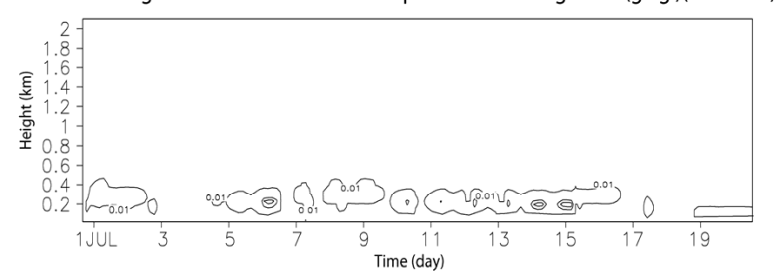

c Time-height cross section of cloud-liquid-water mixing ratio $\left(\mathrm{g} \mathrm{kg}^{-}\right)(\mathrm{CSRM}$-LH run)

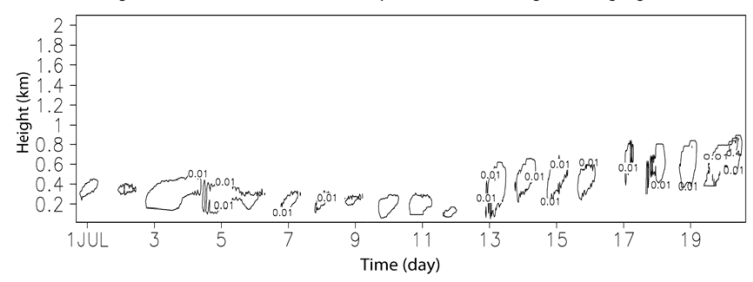

Fig. 7. Time-height cross section of cloud-liquid-water mixing ratio $\left(\mathrm{g} \mathrm{kg}^{-1}\right)$ for (a) the CSRM run, (b) the GCM run, and (c) the CSRM-LH run. Contours are at $0.01,0.4$, and $0.6 \mathrm{~g} \mathrm{~kg}^{-1}$.
Table 2. For each combination, a simulation is carried out with the CSRM radiation scheme (henceforth, referred to as the "CSRM-RAD run") and the simulation is repeated with the GCM radiation scheme (henceforth, referred to as the "GCM-RAD run"). Table 2 shows the net shortwave and longwave radiation fluxes at $20 \mathrm{~km}$ (TOA) and the surface (SFC) for the CSRM-RAD run and the GCM-RAD run for each of the combinations of mixing ratios and effective radii. Those fluxes for the CSRM-RAD run are within $\sim 10 \%$ of those for the GCM-RAD run; this also holds for the individual upward and downward fluxes (not shown). Hence, those radiation schemes can be considered to show nearly identical responses to identical clouds and this supports the assumption that differences in simulations between the CSRM run and the GCM run are mostly caused by differences in cloud schemes.

\subsection{Cloud properties and comparison with observation}

Figures $7 \mathrm{a}$ and $\mathrm{b}$ show the time-height cross section of cloudliquid-water mixing ratio for the CSRM run and the GCM run. Figure 8 a shows the time series of the liquid-water paths (LWPs) for those runs, which are smoothed over 1 day (averaged over the period between $12 \mathrm{~h}$ before and after a time point), and those observed by the Moderate Resolution Imaging Spectroradiometer (MODIS) on the Terra satellite, which are provided as an averaged values over one-day period (for the 10:30 a. m. and 10:30 p. m. crossing times for July 2001 to 2008).

The temporal evolution of the LWP in the CSRM run is much closer to that observed by MODIS than that in the 
a

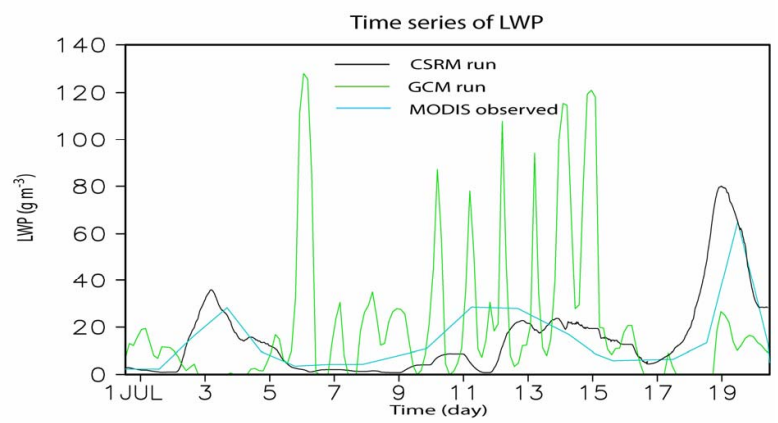

b

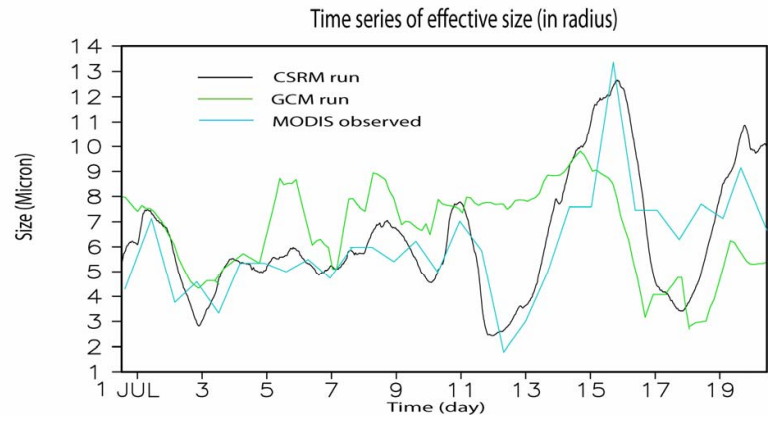

Fig. 8. Time series of (a) LWP $\left(\mathrm{g} \mathrm{m}^{-3}\right)$ averaged over the horizontal domain and (b) effective radius (micron) conditionally averaged over the cloudy regions for the CSRM run, the GCM run, and the MODIS observation.

GCM run. The LWP in the GCM run generally shows much larger temporal fluctuations than the MODIS-observed LWP and the CSRM-run LWP.

Figure $8 \mathrm{~b}$ shows the time series of effective radius of cloud liquid water, conditionally averaged over cloudy regions for the GCM run and the CSRM run, smoothed over 1 day. The MODIS observation of the one-day averaged effective radius is also plotted for comparison. In general, the CSRM-run effective size is closer to the MODIS-observed size than the GCM-run size. For the calculation of the conditional average over the cloudy regions, one needs to determine the grid points within the cloud. Grid points are assumed to be in cloud if the number concentration and volume-mean size of droplets is typical for clouds and fogs $\left(1 \mathrm{~cm}^{-3}\right.$ or more, $1 \mu \mathrm{m}$ or more; Pruppacher and Klett, 1997). The conditional average over the grid points in cloud is obtained at each time step; the conditional average is the arithmetic mean of the variable over the collected grid points in cloud (grid points in clear air are excluded from the collection).

It should be noted that there is an uncertainty associated with the retrieval of the MODIS LWP and droplet size. Generally, the retrieval errors are $\sim 10 \%$ for LWP and droplet size according to Juárez et al. (2009). Hence, the qualitative nature of the differences in LWP and droplet size among the CSRM run, the GCM run, and the MODIS observation shown here is not likely to depend on the uncertainty.

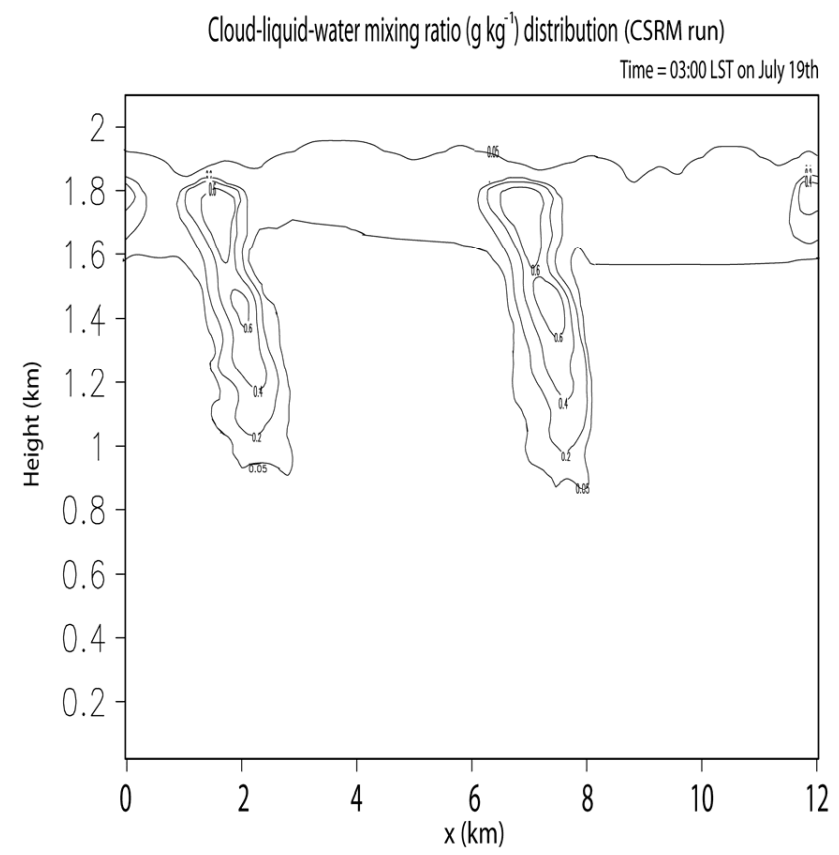

Fig. 9. Contours of cloud-liquid-water mixing ratio $\left(\mathrm{g} \mathrm{kg}^{-1}\right)$ at the time of the occurrence of maximum depth of the averaged cloudliquid-water mixing ratio (03:00 LST 19 July) along the $x$ (eastwest) direction in the middle of the $y$ (north-south) direction in the CSRM run. Contours are at $0.05,0.2,0.4$, and $0.6 \mathrm{~g} \mathrm{~kg}^{-1}$.

Around 00:00 LST on 13 July, cloud depth and height start to increase in the CSRM run, whereas they do not show significant changes in the GCM run (Fig. 7a and b). Around 00:00 LST on 17 July, the depth of the domain-averaged cloud-liquid-water mixing ratio start to increase substantially and the cloud tops reach $\sim 2 \mathrm{~km}$ around 03:00 LST on 19 July (Fig. 7a). This is due to the transition of the cloud type from the stratocumulus cloud simulated earlier in the time period to a cumulus cloud. Figure 9 shows the contours of cloudliquid-water mixing ratio $\left(\mathrm{g} \mathrm{kg}^{-1}\right)$ along the $\mathrm{x}$ (east-west) direction at the time of the occurrence of the maximum depth of the averaged cloud-liquid-water mixing ratio (03:00 LST 19 July) in the middle of the $y$ (north-south) direction in the CSRM run. These contours indicate the development of cumulus clouds whose liquid-water detrains to form stratiform clouds around the MBL top. This transition leads to a substantial increase in the LWP in the CSRM run, making the LWP in the CSRM run much larger than that in the GCM run after around 00:00 LST on 17 July (Fig. 8a). This leads to a better agreement between the MODIS-observed LWP and the CSRM-run LWP. The averaged LWP over time and the horizontal domain after 00:00 LST on 17 July is 7.6, 30.3, and $26.2 \mathrm{~g} \mathrm{~m}^{-2}$, for the GCM run, CSRM run, and the MODIS observation, respectively. The larger CSRM-run LWP also leads to larger upward shortwave radiation at the TOA (leading to a smaller magnitude of net shortwave radiation, which 


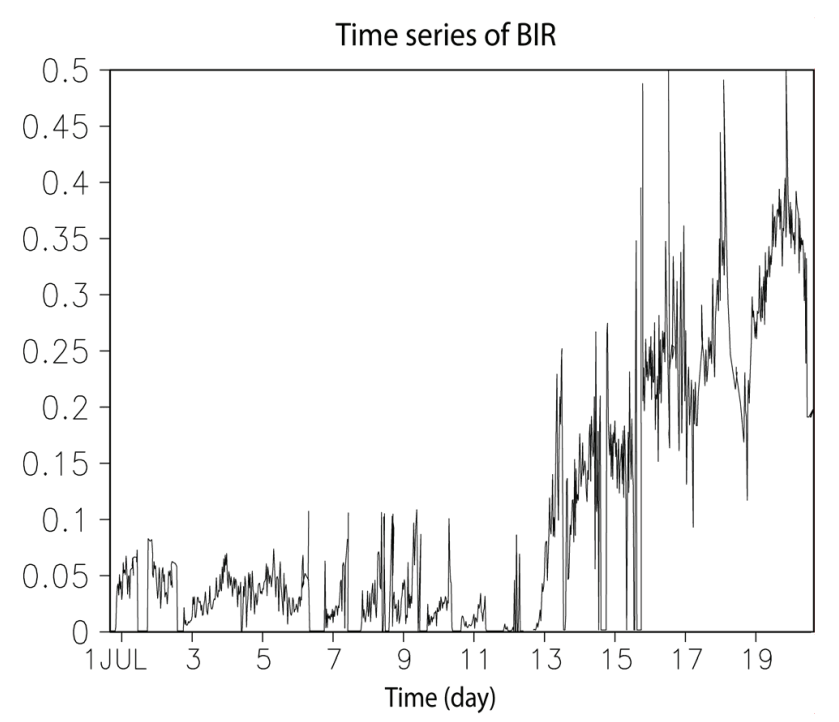

Fig. 10. Time series of BIR averaged over the horizontal domain for the CSRM run.

is downward, at the TOA and the SFC) in the CSRM run after 00:00 LST on 17 July despite the generally larger droplet size in the CSRM run than in the GCM run after 00:00 LST on 17 July (Fig. 8b). The cloud fraction averaged over all the time steps and a layer between minimum cloud-base height and maximum cloud-top height in the CSRM (GCM) run after 00:00 LST 17 July is $0.75(0.55)$. At time steps when clouds are absent, the lifting condensation level (LCL) and the MBL top replace the minimum cloud-base height and maximum cloud-top height, respectively, for the calculation of the cloud fraction. Thus the larger cloud fraction associated with the transition to cumulus clouds contributes to larger upward shortwave radiation at the TOA in tandem with the LWP in the CSRM run after 00:00 LST 17 July. The area-averaged net shortwave radiation at the TOA and the SFC after 00:00 LST 17 July are $-322.5(-430.2)$ and $-202.8(-320.2) \mathrm{W} \mathrm{m}^{-2}$ in the CSRM (GCM) run, respectively. Note that a minus indicates the downward fluxes.

Next, an analyses of the mechanisms that induce the transition from the stratocumulus clouds to the cumulus clouds in the CSRM run is discussed.

\subsection{Transition from stratocumulus to cumulus}

Figure 10 shows the time series of the buoyancy integral ratio (BIR) of Bretherton and Wyant (1997) (hereafter BW97) (see Eq. (14) in BW97 for the details of the BIR) in the CSRM run. The BIR is defined as the ratio of the integral of the magnitude of buoyancy fluxes over the regions of negative buoyancy below cloud base to the integral of the buoyancy fluxes over all other regions. For the calculation of the BIR, when clouds are absent, the LCL replaces the cloud base. Figure 7 a shows cloud thinning or clearing due to the a

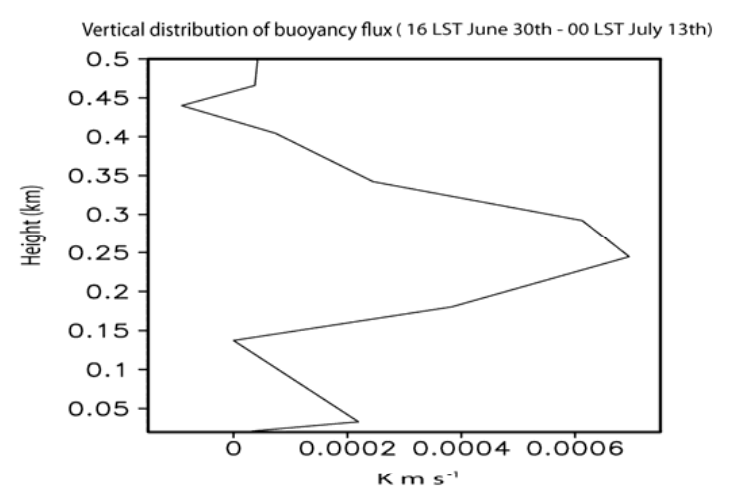

b

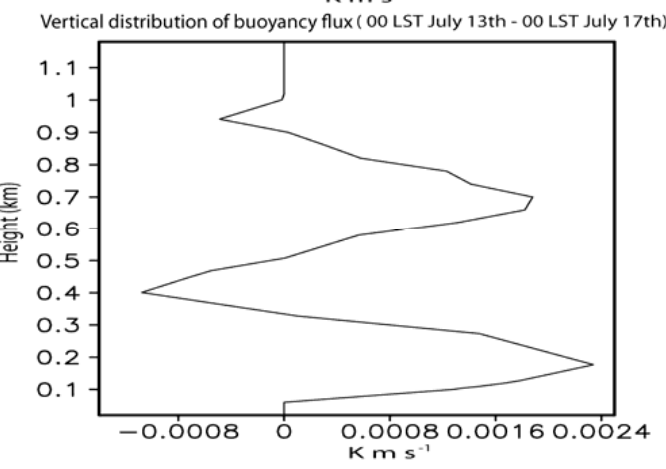

c

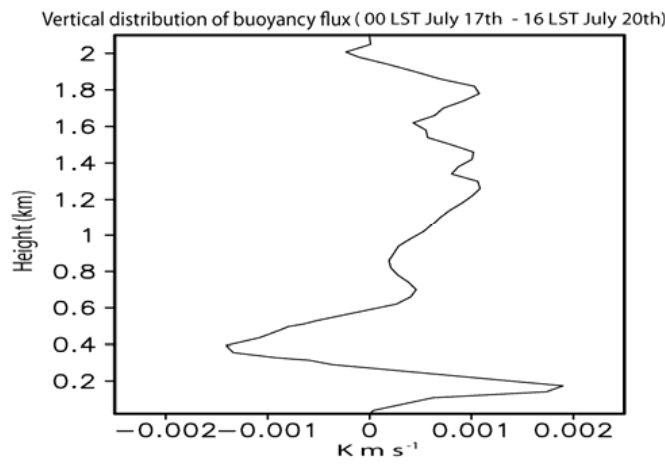

Fig. 11. Vertical distribution of the time- and area-averaged buoyancy fluxes $\left(\mathrm{K} \mathrm{m} \mathrm{s}^{-1}\right.$ ) (a) over 16:00 LST 30 June-00:00 LST 13 July, (b) over 00:00 LST 13 July-00:00 LST 17 July, and (c) over 00:00 LST 17 July-16:00 LST July.

decoupling between the cloud layer and the sub-cloud layer driven by shortwave heating during the daytime when the stratocumulus is a dominant cloud type prior to 00:00 LST on 17 July. After the sun sets, longwave cooling at the cloud top revitalizes convection with the reduction of the magnitude of the decoupling.

BW97 considered the MBL decoupled when the BIR exceeded 0.15. The BIR in the CSRMrun starts to increase substantially around 00:00 LST on 13 July when the cloudbase heights start to increase and it is generally above 0.15 after $\sim 02: 00 \mathrm{LST}$ on 14 July. The large BIR (around 0.15 or larger) represents a strong decoupling (with the large subcloud negative buoyancy fluxes) after 00:00 LST on 13 July, 


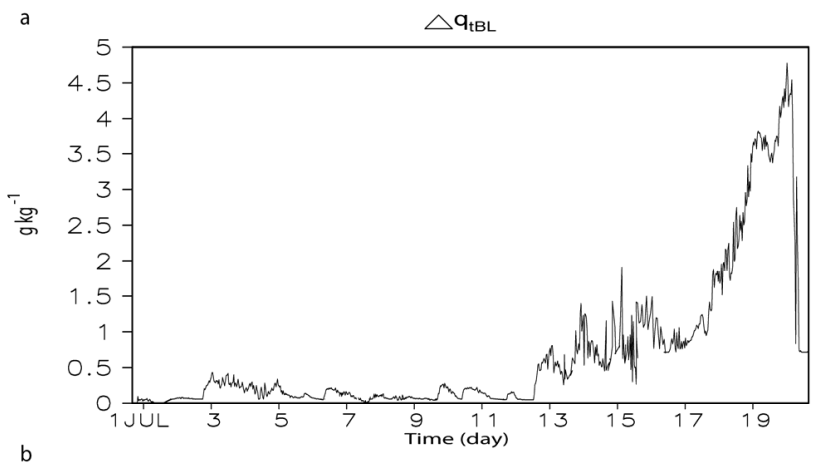

b

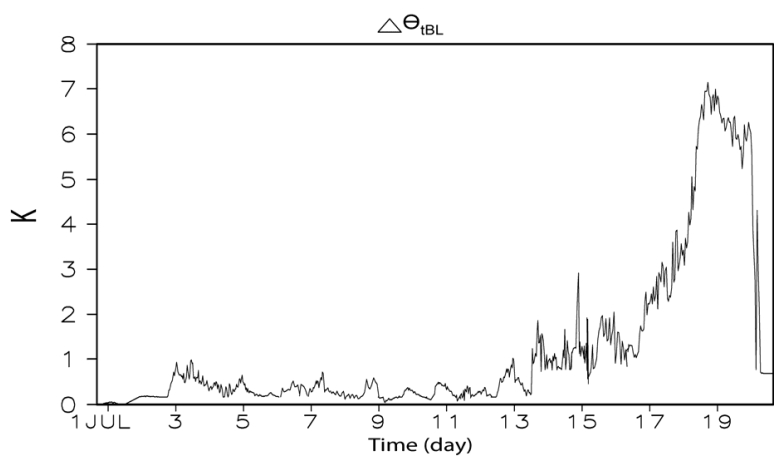

Fig. 12. Time series of averaged (a) $\Delta q_{\mathrm{tBL}}\left(\mathrm{g} \mathrm{kg}^{-1}\right)$ and (b) $\Delta \theta_{\mathrm{tBL}}$ (K) over the horizontal domain for the CSRM run.

as shown in Fig. 11 depicting the vertical distribution of the averaged buoyancy fluxes over three time periods (16:00 LST 30 June-00:00 LST 13 July, 00:00 LST 13 July-00:00 LST 17 July, and 00:00 LST 17 July-16:00 LST 20 July). The buoyancy fluxes are calculated in the same manner as those in Jiang et al. (2002). The negative buoyancy flux is not present in the first time period (when the stratocumulus clouds with low bases are dominant) in Fig. 11a, indicating that decoupling is not active. A large increase in the negative buoyancy flux is shown in the second time period (when the cloudbases of stratocumulus clouds start to increase) in Fig. 11b, indicating the occurrence of decoupling. The negative buoyancy flux reaches its maximum in the third time period (when cumulus clouds begin to develop and become a dominant cloud type), indicating the most active decoupling.

The degree of decoupling can also be assessed by simply estimating the vertical stratification of the total water mixing ratio $\left(q_{t}\right.$; the sum of water-vapor mixing ratio and cloud-liquid-water mixing ratio) and the potential temperature $(\theta)$ following BW97. Starting with the horizontal mean soundings (denoted by $\left\langle q_{t}>\right.$ and $<\theta>$ ), the vertical averages of each in a 75-m thick layer at the surface and in a 75-m thick layer just below the inversion, we define " $\Delta q_{\mathrm{tBL}}$ " and " $\Delta \theta_{\mathrm{BL}}$ " as the differences in $\left.<q_{t}\right\rangle$ and $<\theta>$, respectively, between the surface and the boundary-layer (BL) top:

$\Delta q_{\mathrm{tBL}} \equiv<q_{t}>_{\text {surface }}-<q_{t}>_{\text {BLtop }}$

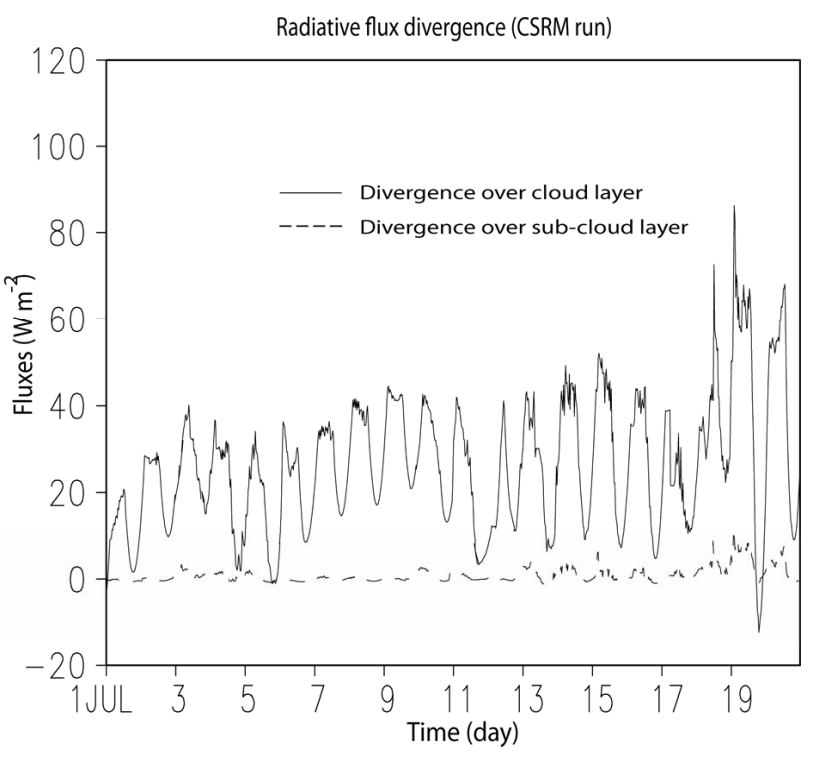

Fig. 13. Time series of averaged (over the horizontal domain) net radiative flux divergence $\left(\mathrm{W} \mathrm{m}^{-2}\right.$ ) over the cloud layer (solid line) and over the sub-cloud layer (dashed line) for the CSRM run. When clouds are not present, the cloud layer is defined as the layer between the LCL and the MBL top.

$\Delta \theta_{\mathrm{tBL}} \equiv<\theta>_{\text {surface }}-<\theta>_{\text {BLtop }}$

Increasing " $\Delta q_{\mathrm{tBL}}$ " or " $\Delta \theta_{\mathrm{tBL}}$ " indicates more decoupling and internal BL stratification. Figure 12 shows both " $\Delta q_{\mathrm{tBL}}$ " and " $\Delta \theta_{\mathrm{tBL}}$ " remain small and relatively constant up to 00:00 LST on 13 July. This indicates that a well-mixed boundary layer is maintained up to 00:00 LST on 13 July (associated with the development of stratocumulus clouds with low bases as shown in Fig. 7a). But, they increase rapidly around 00:00 LST on 13 July when the cloud-base height starts to increase and more rapidly around 00:00 LST on 17 July when cumulus clouds begin to develop, indicating strong decoupling. BW97 pointed out that decoupling (leading to cumulus formation) is mainly due to the increasing latent heat fluxes at the surface.

Figures $3 \mathrm{a}$ and 13 depict the time series of the surface fluxes and the radiative flux divergence (one of the diabatic forcings) for the CSRM run, respectively. The most obvious trend is that the LH flux starts to increase with time around 00:00 LST on 13 July when the cloud-base height and BIR start to increase substantially; prior to 00:00 LST on 13 July, the LH flux does not either increase or decrease significantly. The net radiative flux divergence across the cloud layer of the combined longwave and shortwave radiation is $\Delta F_{R}=F_{R}^{+}-F_{R}\left(z_{b}\right)$. Here, $\mathrm{F}_{R}$ is the net radiation flux where plus and $\mathrm{z}_{b}$ denote the cloud top and base, respectively. When clouds are not present, the cloud layer is defined as the layer between the LCL and the MBL top for the calculation of the flux divergence. The diurnal cycle 


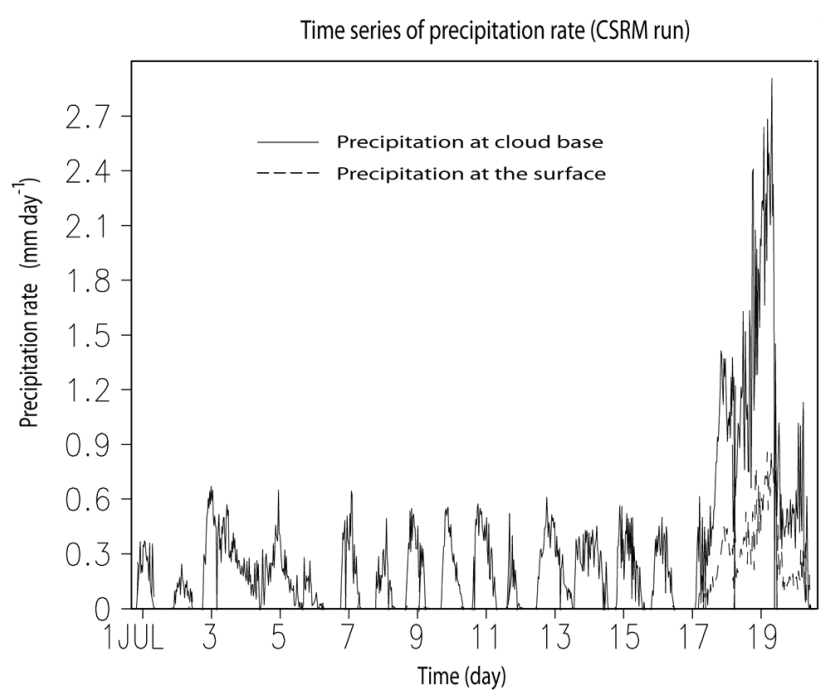

Fig. 14. Time series of area-averaged precipitation rate $\left(\mathrm{mm} \mathrm{day}^{-1}\right)$ at cloud base (or at the LCL when clouds are absent) (solid line) and at the surface (dashed line) for the CSRM run.

of the radiative flux divergence does not vary significantly prior to 00:00 LST on 13 July when the decoupling starts to occur. The divergence across the sub-cloud layer, which is $\Delta F_{R}=F_{R}\left(z_{b}\right)-F_{R}(0)$ (where 0 denotes the surface), is less than $\sim 2 \mathrm{~W} \mathrm{~m}^{-2}$ prior to 00:00 LST on 13 July (Fig. 13). This indicates a slight radiative warming of the subcloud layer. The diurnal cycle of precipitation at cloud base (or at the LCL when clouds are absent) also does not vary significantly, indicating that the latent heating in the cloud layer due to the formation of precipitation does not vary much prior to 00:00 LST on 13 July (Fig. 4). All precipitation evaporates before reaching the surface, leading to no surface precipitation prior to 00:00 LST on 13 July (Fig. 14). Thus, the net latent heating of the MBL due to precipitation is zero prior to 00:00 LST on 13 July. The evaporation of precipitation substantially reduces the difference between the diabatic cooling in the cloud layer and that below, inhibiting the completion of convection from the surface to the MBL top and promoting decoupling. However, the diabatic cooling (in the cloud and sub-cloud layers) does not change greatly during the coupled phase as shown in Figs. 13 and 14. This indicates that diabatic forcings do not explain the occurrence of decoupling. The large-scale temperature and humidity forcings also do not show substantial changes up to 00:00 LST on 13 July (Fig. 2). Figure 15 shows the area-averaged largescale vertical velocity at the MBL top and it does decrease around 00:00 LST on 13 July, which is when the increase in subsidence occurs. This counters the increase in cloud-base and -top heights around 00:00 LST on 13 July.

The above analyses of the variables associated with the MBL energy budgets and the large-scale subsidence indicate that the surface LH flux is a primary candidate for strong

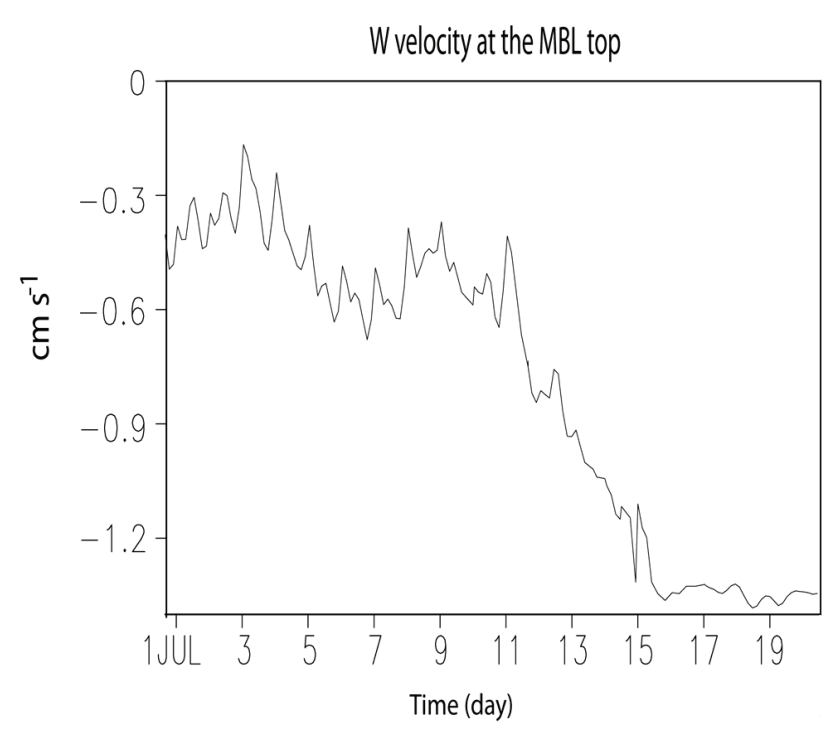

Fig. 15. Time series of area-averaged large-scale vertical velocity (w) $\left(\mathrm{cm} \mathrm{s}^{-1}\right)$ at the MBL top for the CSRM run.

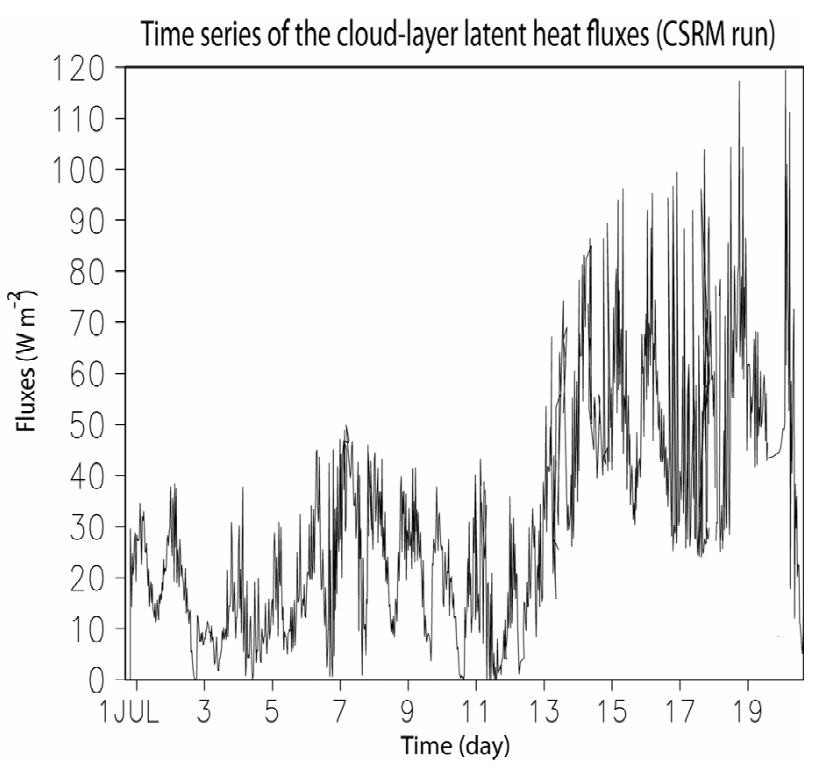

Fig. 16. Time series of the cloud-layer averaged LH fluxes for the CSRM run. When clouds are not present, the cloud layer is defined as a layer between the LCL and the MBL top.

decoupling that starts around 00:00 LST on 13 July, leading to the development of cumulus clouds after 00:00 LST on 17 July. Note that the surface LH flux shows the largest changes around 00:00 LST on 13 July among variables associated with the MBL energy budgets (Fig. 3a), indicating it drives increases in in-cloud buoyancy fluxes after around 00:00 LST on 13 July as shown in the comparison between Fig. 11a and b. Figure 16 shows the time series of cloud-layer 
averaged latent heat flux. Here, when clouds are not present, the cloud layer is defined as a layer between the LCL and the MBL top as in the calculation of the radiative divergence. The averaged latent heat fluxes start to increase substantially around 00:00 LST on 13 July when the surface LH fluxes start to increase, contributing to the increase in incloud buoyancy fluxes and thus the buoyancy jump around the cloud base and the decoupling as shown in Fig. 11b. This supports the leading role of the LH fluxes in the development of decoupling and cumulus clouds.

As reported in BW97 and shown in this study, upward latent heat fluxes in the boundary layer increase with an increase in the surface latent heat fluxes. This increases the buoyancy fluxes and turbulence levels within the cloud, creating more entrainment per unit of cloud radiative cooling. The increased entrainment leads to increasingly negative buoyancy fluxes below cloud base associated with a downward flux of warm entrained air as shown in Fig. 11b. BW97 explained that this disrupted the mixed layer and created a weak stable layer below cloud base, leading to the development of conditionally unstable cloud layer. The stable layer acted as a valve that allowed only the most powerful subcloud-layer updrafts to penetrate up to the main stratocumulus cloud base, leading to the development of cumulus clouds. As the decoupling became more pronounced, the cumulus clouds developed more.

To confirm the major role of the latent heat fluxes in the development of strong decoupling and cumulus clouds, an additional simulation is performed. This simulation is identical to the CSRM run except that a different surface latent heat flux is applied after 00:00 LST on 13 July. Figure 3b depicts the latent heat flux applied to this additional simulation (henceforth, referred to as the "CSRM-LH" run). As seen in the comparison between Fig. 3a and b, the surface latent heat flux does not increase and is set to the same value as at 00:00 LST on 13 July for this additional simulation after 00:00 LST on 13 July when cloud-base and -top heights both start to increase in the CSRM run. As seen in Fig. 7c, cumulus clouds do not develop after 00:00 LST 17 July in this simulation, supporting the notion the increase in the surface latent heat flux is the impetus for the development of strong decoupling and cumulus clouds after 00:00 LST on 13 July.

\subsection{Liquid-water budget of stratocumuls clouds in the CSRM run}

A smaller LWC and thus LWP is simulated in the CSRM run than that in the GCM run from 16:00 LST on 30 June to 00:00 LST on 17 July before the development of cumulus. The time- and domain-averaged LWP prior to 00:00 LST on 17 July is 24.3 and $10.3 \mathrm{~g} \mathrm{~m}^{-2}$ for the GCM run and the CSRM run, respectively. This contributes to a smaller upward shortwave radiation at the TOA and thus a larger magnitude of the net shortwave radiation, which is downward, at TOA and SFC, respectively, despite the smaller droplet size
(Fig. 8b) and larger cloud fraction in the CSRM run than in the GCM run. The averaged cloud fraction is $0.61(0.59)$ in the CSRM (GCM) run. The cloud fraction here is calculated in the same manner as explained in Sect. 6.2 except that the average is over the period between 16:00 LST on 30 June and 00:00 LST on 17 July. The time- and area-averaged net shortwave radiation flux at the TOA and the SFC over the period between 16:00 LST on 30 June and 00:00 LST on 17 July are $-423.6(-324.3)$ and $-351.2(-193.5) \mathrm{W} \mathrm{m}^{-2}$ in the CSRM (GCM) run, respectively.

The smaller LWC in the CSRM run than in the GCM run leads to a better agreement in the LWP between the CSRM run and the MODIS observation. The time-averaged LWP prior to 00:00 LST on 17 July is $12.3 \mathrm{~g} \mathrm{~m}^{-2}$ for the MODIS observation.

The LWPs prior to 00:00 LST on 17 July are less than $50 \mathrm{~g} \mathrm{~m}^{-2}$. Hence, stratocumulus clouds here can be considered thin according to the classification of Turner et al. (2007). As shown in Lee et al. (2009), condensation plays a critical role in the determination of the LWC and LWP in thin clouds. Other processes such as autoconversion, collection, and sedimentation play a negligible role in the determination of the LWC and LWP.

To elucidate the microphysical processes controlling the LWC and LWP of the stratocumulus clouds in the CSRM run before the development of cumulus clouds, domain-averaged cumulative sources (i.e. condensation) and sinks of cloud liquid water (the small-cloud-droplet mode + the large-clouddroplet mode) were obtained. For this, the production equation for cloud liquid water is integrated over the domain and over the period between 16:00 LST 30 June and 00:00 LST 17 July. Those integrations are denoted by $<>$ :

$$
<A>=\frac{1}{L x L y} \iiint \rho_{a} A d x d y d z d t
$$

where $L x$ and $L y$ are the domain length $(12 \mathrm{~km})$, in east-west and north-south directions, respectively. $\rho_{a}$ is the air density and $A$ represents any of the variables in this study. The budget equation for cloud liquid water is as follows:

$$
\begin{aligned}
& <\frac{\partial q_{c}}{\partial t}>=<Q_{\text {cond }}>-<Q_{\text {evap }}>-<Q_{\text {auto }}>-<Q_{\text {accr }}> \\
& \begin{array}{lllll}
0.033 & 0.34 & 0.30 & 0.00024 & 0.0071 \mathrm{~mm}
\end{array}
\end{aligned}
$$

Here, $q_{c}$ is cloud-liquid-water mixing ratio. $Q_{\text {cond }}, Q_{\text {evap }}$, $Q_{\text {auto, }}$, and $Q_{\text {accr }}$ refer to the rates of condensation, evaporation, autoconversion of cloud liquid water to rain, and accretion of cloud liquid water by rain, respectively.

The budget numbers beneath Eq. (7) show that condensation and evaporation are $\sim$ one to three orders of magnitude larger than autoconversion and accretion as also shown in Lee et al. (2009). This indicates that the conversion of cloud liquid water (produced by condensation) to rain is highly inefficient.

The terminal fall velocity of cloud particles to which the sedimentation rate is proportional increases with their increasing size. Also, the sedimentation of cloud mass 
is mainly controlled by the sedimentation of cloud particles larger than the critical size for collisions around $\sim 20$ $\sim 40 \mu \mathrm{m}$ in radius (Pruppacher and Klett, 1997). Cloud mass here is the sum of the mass of all species associated with warm microphysics, i.e. the small-cloud-droplet mode, the large-cloud-droplet mode, and rain. Autoconversion and accretion are processes that control the growth of cloud particles after they reached around the critical size or larger (Rogers and Yau, 1989). Hence, the small contribution of autoconversion and accretion to the LWC implies that the role of sedimentation of cloud particles in the determination of the LWC is not as significant as that of condensation and evaporation.

Figure $17 \mathrm{a}$ and $\mathrm{b}$ show the time- and area-averaged vertical distribution of condensation and cloud-mass changes due to sedimentation over the period before the development of cumulus clouds for the CSRM run. The vertical coordinate is in the units of the height normalized with respect to the cloud-top height $\left(\mathrm{z}_{t}\right)$ and the CSRM $\times 2$ run in Fig. $17 \mathrm{~b}$ will be discussed in the following section. Cloud mass here is the sum of the mass of all species associated with warm microphysics, i.e. the small-cloud-droplet mode, the large-clouddroplet mode, and rain. The magnitude of the condensation rate is substantially larger than that of the sedimentationinduced cloud-mass changes for the CSRM run (Fig. 17a and b). Hence, as implied by the budget analysis, the LWC and LWP are strongly controlled by condensation and the role of sedimentation in the LWC and LWP is negligible. Cloud liquid water formed by condensation eventually disappears via evaporation. Since very small portion of cloud liquid water (produced by condensation) converts to rain via autoconversion and accretion before its disappearance, condensation controls most of cloud liquid water as a source of evaporation. Hence, condensation induces much larger evaporation than autoconversion, accretion, and sedimentation (Eq. 7).

\subsection{Effects of cloud-base instability and interactions between CDNC and condensation on LWP in the CSRM run}

The surface precipitation is absent in the CSRM run when stratocumulus is a dominant cloud type before the development of cumulus clouds (Figs. 7a and 14). When precipitation reaches the surface, cooling from rain evaporation occurs from the cloud base to the surface. This tends to stabilize the entire layer below stratiform clouds (Paluch and Lenschow, 1991). However, when precipitation does not reach the surface, its evaporation and the associated cooling increase instability around the base of the stratiform clouds, leading to increases in updrafts and downdrafts in the cloud and sub-cloud layers (Feingold et al., 1996). As indicated by Jiang et al. (2002), when precipitating particles evaporate completely before reaching the surface, even the slightly increased evaporation of precipitation around the cloud base can cause the increased instability concentrated around the cloud base (leading to increased updrafts and condensation) in stratiform clouds. To examine this instability effect, a supplementary simulation was carried out. This supplementary simulation is referred to as the "CSRM $\times 2$ run" henceforth. The CSRM $\times 2$ run is identical to the CSRM run except that aerosols are increased by a factor 2 , hence, the CSRM $\times 2$ is expected to have different in-cloud rain formation and its cloud-base evaporation (leading to a different cloud-base instability) as compared to those in the CSRM run. Those two runs are compared over the period between 16:00 LST on 30 June and 00:00 LST on 17 July when the stratocumulus cloud is the dominant cloud type.

Figure 18 is the time series of cumulative condensation averaged over the horizontal domain for the CSRM run and the CSRM $\times 2$ run. Before around 00:00 LST on 6 July, condensation is smaller in the CSRM run than in the CSRM $\times 2$ run, leading to the larger LWC and thus LWP $\left(12.3 \mathrm{~g} \mathrm{~m}^{-2}\right)$ in the $\mathrm{CSRM} \times 2$ run, which is $10 \%$ larger than that in the CSRM run. However, due to rapidly increasing condensation around 00:00 LST on 5 July, cumulative condensation becomes larger around 00:00 LST 6 July in the CSRM run than in the CSRM $\times 2$ run. This leads to the larger timeand domain-averaged LWC and thus LWP $\left(9.8 \mathrm{~g} \mathrm{~m}^{-2}\right)$ in the CSRM run over the period between 16:00 LST on 30 June and 00:00 LST on 17 July, which is 15\% larger than those in the $\mathrm{CSRM} \times 2$ run.

Figure $17 \mathrm{~b}$ and $\mathrm{c}$ depict the domain-averaged sedimentation-induced cloud mass change and rain evaporation in the CSRM run and the CSRM $\times 2$ run. They confirm that precipitation do not reach the surface and that rain evaporates mostly around cloud base (at $\mathrm{z} / \mathrm{z}_{t} \sim 0.4$ to 0.5$)$ in both the CSRM run and the CSRM $\times 2$ run. Increased aerosols in the $C S R M \times 2$ run delay the formation of precipitation, leading to smaller precipitation and thus its evaporation around cloud base. As shown in Fig. $17 \mathrm{~d}$, depicting the vertical profile of the time- and area-averaged rate of conversion of cloud liquid water to rain, more droplets are converted to rain in the CSRM run. The conditionally averaged effective size (in diameter) of cloud droplets over all of grid points in clouds over period between 16:00 LST on 30 June and 00:00 LST on 17 July is 16 and $10 \mu \mathrm{m}$ in the CSRM run and in the CSRM $\times 2$ run, respectively. When droplets grow above $80 \mu \mathrm{m}$ in diameter, they are classified as rain. Hence, the precipitation threshold is $80 \mu \mathrm{m}$ in diameter, since the terminal velocity of small and large cloud droplets is very small as compared to that of rain. These averaged effective sizes much smaller than the precipitation threshold corroborate the fact that no precipitation reaches the surface in both the simulations. Larger particle size favors more efficient collisions among droplets leading to a higher conversion of droplets to rain. Hence, more rain drops with higher terminal velocity than droplets precipitate to around the cloud base more in the CSRM than in the CSRM $\times 2$ run. This in turn leads to larger evaporation of rain just below the cloud base as shown in 
a

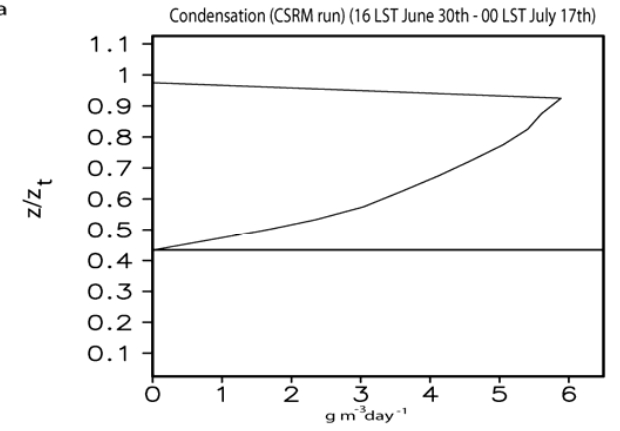

b

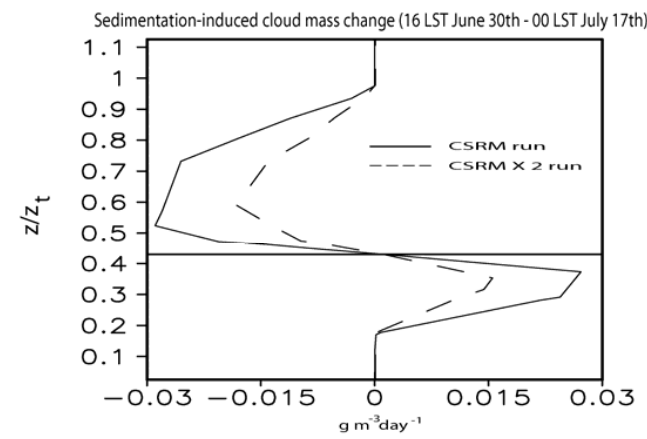

c

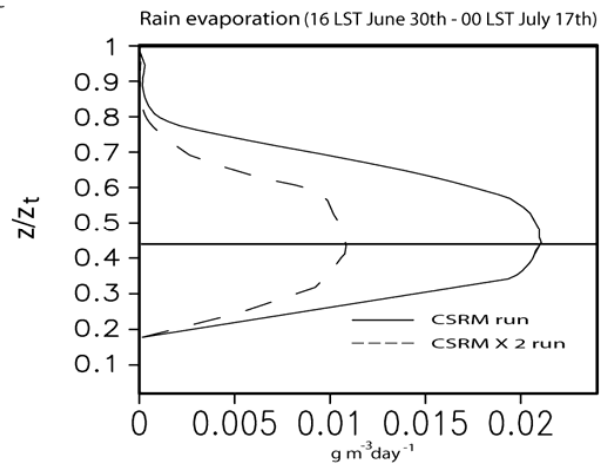

d
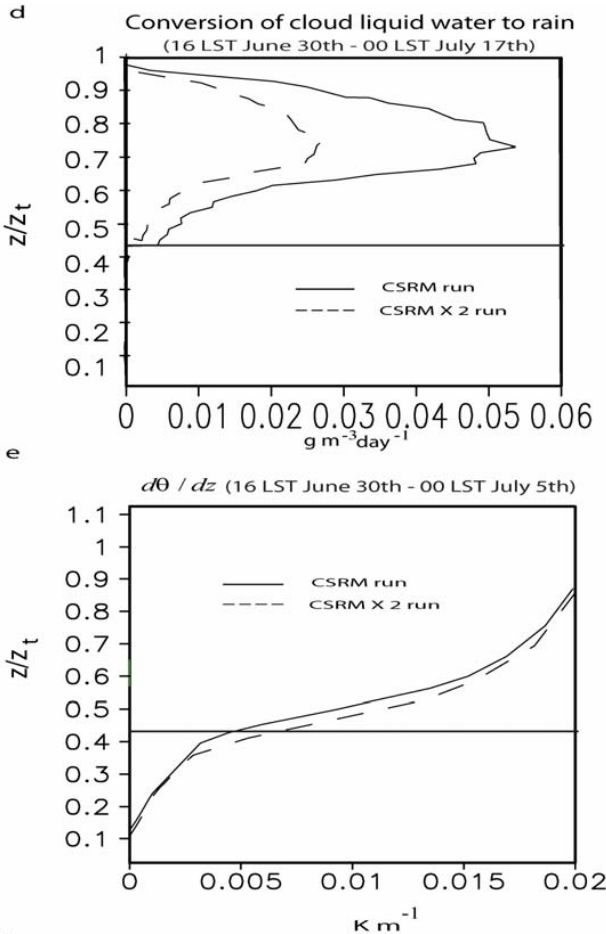

f

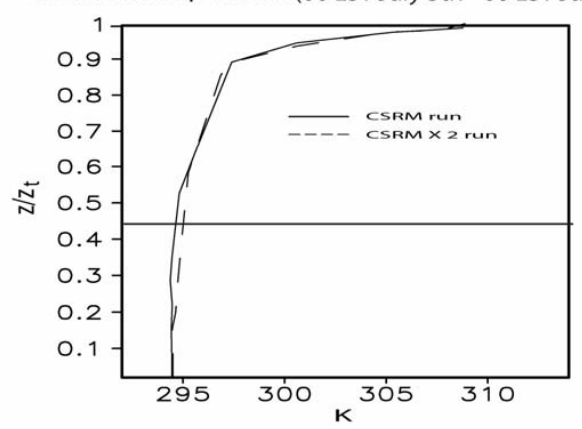

9 Variance of vertical velocity $\left(\overline{W^{\prime} W^{\prime}}\right)$ (00 LST July 5th - 00 LST July 6th)

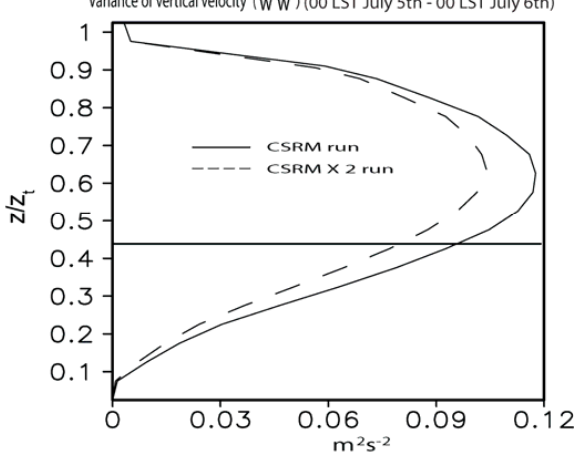

Fig. 17. Vertical distribution of time- and area-averaged (a) condensation for the CSRM run, (b) sedimentation-induced cloud mass change, (c) rain evaporation, and (d) conversion of cloud liquid water to rain in $\mathrm{g} \mathrm{m}^{-3} \mathrm{day}^{-1}$ for the CSRM run and the CSRM $\times 2$ run over 16 LST 30 June-00 LST 17 July. (e), (f), and (g) are the vertical distribution of time- and area-averaged $\frac{d \theta}{d z}\left(\mathrm{~K} \mathrm{~m}^{-1}\right), \theta(\mathrm{K})$, and $^{\prime} w^{\prime}\left(\mathrm{m}^{-2} \mathrm{~s}^{-2}\right)$, respectively, for the CSRM run and the CSRM $\times 2$ run. (e) is averaged over 16:00 LST 30 June-00:00 LST 5 July and (f) and (g) are averaged over 00:00 LST 5 July-00:00 LST 6 July. The solid horizontal line in each figure is the average cloud-base height normalized with respect to cloud-top height $\left(\mathrm{z}_{t}\right)$. 


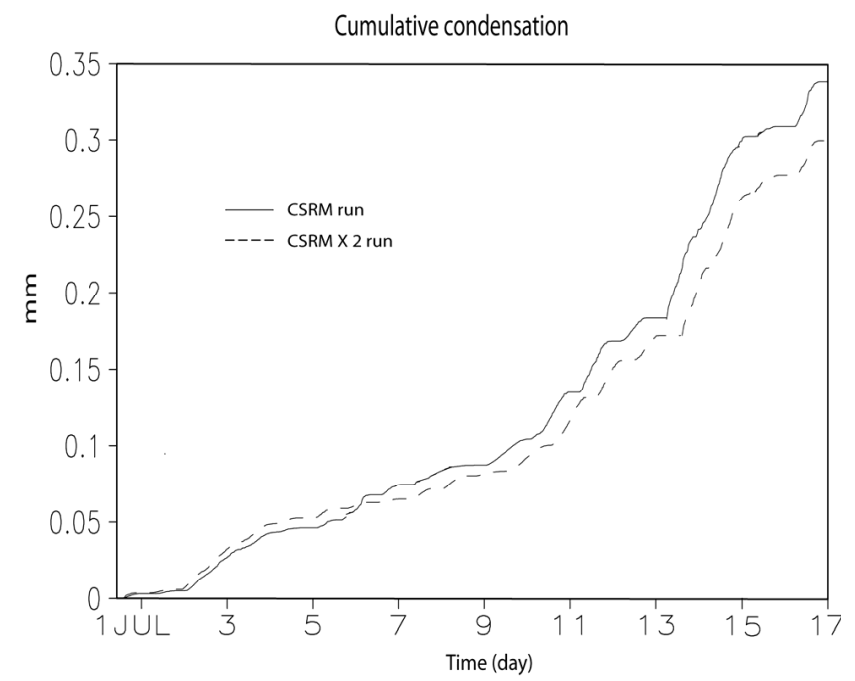

Fig. 18. Time series of cumulative condensation $(\mathrm{mm})$ averaged over the horizontal domain for the CSRM run and the CSRM $\times 2$ run prior to 00:00 LST 17 July.

Fig. 17c. Figure 17e, depicting the area-averaged profile of lapse rate $\frac{d \theta}{d z}$ over 16:00 LST on 30 June-00:00 LST on 5 July, shows that the increase in evaporation below cloud base leads to larger instability in the CSRM run prior to 00:00 LST 5 July ( $\frac{d \theta}{d z}$ is smaller in the CSRM run below cloud base). Here, $\theta$ is potential temperature. Figure $17 \mathrm{f}$ shows the domain-averaged profile of potential temperature over 00:00 LST on 5 July-00:00 LST on 6 July. Smaller $\frac{d \theta}{d z}$ below cloud base leads to lower potential temperature in the CSRM run around cloud base. This larger instability drives a larger variance of vertical air motion $\left(\overline{w^{\prime} w^{\prime}}\right)$ (associated with the larger updrafts and downdrafts) in the CSRM run than in the CSRM $\times 2$ run in the MBL over 00:00 LST on 5 July00:00 LST on 6 July as shown in Fig. 17g which depicts the averaged $\overline{w^{\prime} w^{\prime}}$ over 00:00 LST on 5 July-00:00 LST on 6 July. Stronger vertical motion leads to the rapidly increasing condensation around 00:00 LST on 5 July and then to larger cumulative condensation around 00:00 LST on 6 July (leading to a larger LWP) in the CSRM run than in the CSRM $\times 2$ run (Fig. 18).

Among the variables associated with the condensational growth of droplets, differences in the supersaturation and the CDNC contribute most to the differences in condensation between the CSRM run and the CSRM $\times 2$ run. Percentage differences in the other variables in the growth equation of droplets (see Eq. 2) are found to be approximately two orders of magnitude smaller than those in supersaturation and CDNC throughout the simulations. Figure 19a shows the time series of CDNC and Fig. 19b the time series of supersaturation, conditionally averaged over areas where the condensation rate $>0$, for the CSRM and the CSRM $\times 2$ run, respectively. Here, the conditional average is the arithmetic mean of the variable over collected grid points with the

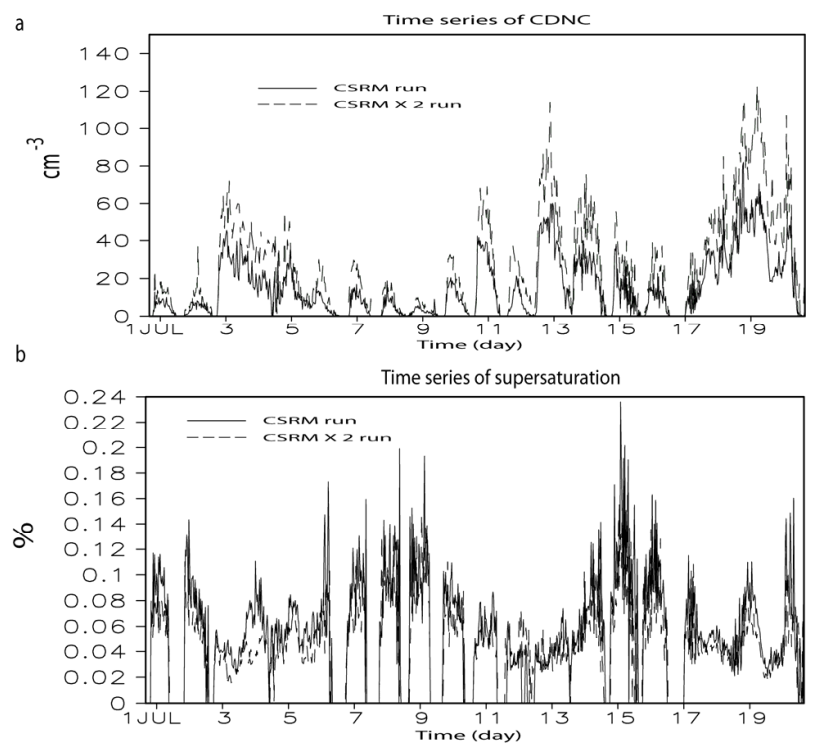

Fig. 19. Time series of conditionally averaged (a) $\mathrm{CDNC}\left(\mathrm{cm}^{-3}\right)$ and (b) supersaturation (\%) over areas where the condensation rate $>0$ for the $\mathrm{CSRM}$ run and the $\mathrm{CSRM} \times 2$ run.

condensation rate $>0$ (grid points with the zero condensation rate are excluded from the collection). Figure $19 \mathrm{~b}$ indicates that supersaturation is generally larger in the CSRM run than in the $\mathrm{CSRM} \times 2$ run. However, the condensation rate (indicated by the slope of cumulative condensation) is generally higher, leading to larger cumulative condensation in the CSRM $\times 2$ run than in the CSRM run (Fig. 18) prior to around 00:00 LST 6 July. As found by Lee et al. (2009), this is ascribed to the larger CDNC (as shown in Fig. 19a) providing a larger surface area of droplets for water-vapor condensation in the CSRM $\times 2$ run as compared to that in the CSRM run. With increasing aerosols, the effects of the CDNC increase on the surface area of droplets and thus on condensation compete with the effects of the supersaturation decrease on condensation with increasing aerosols. This leads to a smaller condensation difference than the CDNC and supersaturation differences. The effects of the increased surface area on condensation outweigh those of the decreased supersaturation, leading to the increase in the condensation in the $\mathrm{CSRM} \times 2$ run than in the CSRM run prior to around 00:00 LST on 6 July. However, the larger cloud-base instability outweigh the weaker interactions among CDNC, supersaturation, and condensation in the CSRM run than in the $\mathrm{CSRM} \times 2$ run, leading to the larger condensation and LWP after around 00:00 LST 6 July.

It is notable that, when conditionally averaged over gird points with the condensation rate $>0$, the effective sizes are 14 and 12 micron (in diameter) for the CSRM run and the $\mathrm{CSRM} \times 2$ run, respectively. The mass of a $12-\mu \mathrm{m}$ droplet in the CSRM $\times 2$ run is $\sim 40 \%$ smaller than the mass of a $14-\mu \mathrm{m}$ droplet in the CSRM run. Hence, if we consider 
this difference without taking into account the interactions among varying CDNC, supersaturation, and cloud-base instability with varying aerosols to explain the difference in LWC, the difference in LWC between the CSRM run and the $\mathrm{CSRM} \times 2$ run is $\sim 2.5$ times larger than that simulated here. This indicates that simply relying on changes in particle size without considering these interactions can overestimate the effects of aerosols on LWC and thus LWP.

The comparison between the CSRM run and the CSRM $\times 2$ run demonstrates that rain evaporation affects the cloud-base instability which in turn affects the dynamics and thus condensation and the LWP in the CSRM run. The sensitivity of variables other than the CDNC and the supersaturation in the growth equation of droplets (Eq. 2) to the different microphysical and cloud-scale meteorological conditions between the CSRM run and the $\mathrm{CSRM} \times 2$ run is negligible as compared to that of the CDNC and the supersaturaion. This demonstrates that the condensation is controlled by the interactions between the varying CDNC (representing the spatiotemporal variation of a microphysical factor for condensation) and the varying supersaturation (representing the spatiotemporal variation of meteorological factors for condensation) in the CSRM run. This interacts with the feedbacks between the rain evaporation and the cloud-base instability for the determination of the LWP in the CSRM run.

\subsection{Cloud liquid water in the GCM run}

The CSRM run and the GCM run are under the identical environmental conditions which are characterized by initial conditions, large-scale forcings, and surface fluxes. Also, the radiative divergence and precipitation (not shown) do not change significantly up to 00:00 LST on 13 July in the GCM run as they do not in the CSRM run; the minimum and maximum values of diurnal variations of the divergence and precipitation do not vary substantially. This indicates that the GCM-simulated clouds have similar energy budget conditions to those in the CSRM-simulated clouds. However, deepening-warming decoupling leading to the development of cumulus clouds is not simulated in the GCM run; note that this leads to much smaller LWP in the GCM run as compared to the MODIS observation and the CSRM run, while the CSRM-run LWP shows a good agreement with the MODIS-observed LWP after 00:00 LST on 17 July. This is because the GCM used here is not able to resolve cloud-scale turbulent motions, which in turn makes it impossible to simulate interactions among latent heat fluxes, buoyancy fluxes, and entrainments in the GCM run.

The autoconversion and collection parameterizations using a fixed threshold and the a constant collection efficiency in the GCM run lead to a larger conversion efficiency (i.e. the ratio of the conversion of cloud liquid water to rain to condensation) as compared to the CSRM run using a size-dependent collection efficiency. Note that the double-moment microphysics scheme in the CSRM run uses a

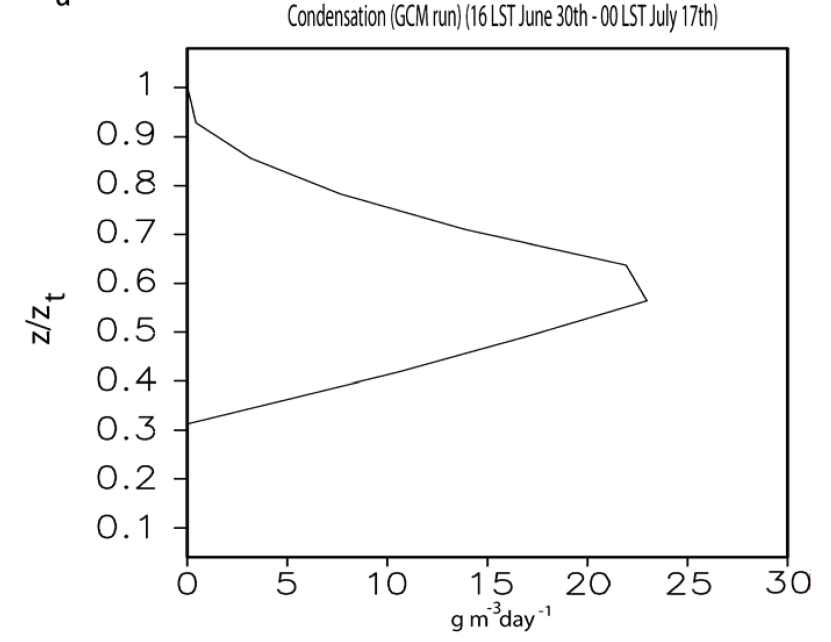

b

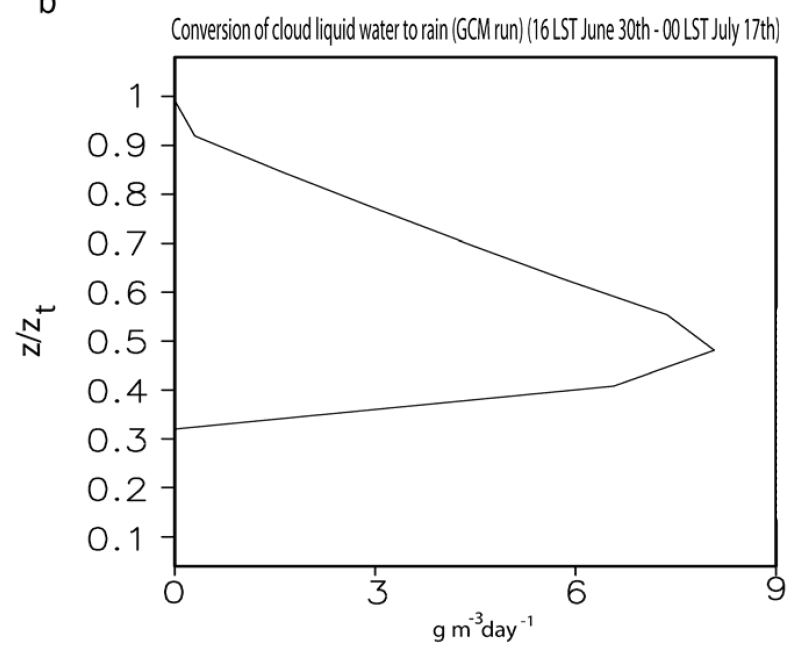

Fig. 20. Vertical distribution of the time- and area-averaged (a) condensation and (b) conversion of cloud liquid water to rain $\left(\mathrm{g} \mathrm{m}^{-3} \mathrm{day}^{-1}\right.$ ) over 16:00 LST 30 June-00:00 LST 17 July for the GCM run.

the full stochastic collection solutions with realistic collection kernels described in Saleeby and Cotton (2004); when drops grow above 20 micron and 40 micron in radius through collection they are re-classified as large cloud droplets and raindrops in the CSRM run. Figure 20 shows the vertical distribution of the time- and area-averaged condensation and the conversion of cloud liquid water to rain (i.e. autoconversion + collection of cloud liquid water by rain) over the time period from 16:00 LST on 30 June to 00:00 LST on 17 July when stratocumulus clouds are the dominant cloud type for both the runs. Figure 20 indicates that condensation is $~ 4$ times larger in the GCM run as compared to condensation in the CSRM run shown in Fig. 17a prior to 00:00 LST on 17 July. Condensation is combined with evaporation in the cloud parameterization in the GCM run (Zhang et al., 
2003). Hence, to separate condensation from evaporation, it is assumed that evaporation does not occur when the vertical velocity $>0$ and, thus, condensation is calculated only when the vertical velocity $>0$ in the GCM run. Figure 20 also indicates that the conversion efficiency is $\sim 30 \%$, which is $\sim$ one order of magnitude larger than that simulated in the CSRM run prior to 00:00 LST on 17 July. The larger condensation and conversion efficiency result in substantially larger LWP (which is less close to the observed LWP than that in the CSRM run) and the presence of precipitation prior to 00:00 LST on 17 July when cumulus clouds start to develop in the CSRM run. The time- and area-averaged precipitation rate is $1.1 \mathrm{~mm} \mathrm{day}^{-1}$ in the GCM run prior to 00:00 LST on 17 July. The increased condensation is large enough to result in a larger LWP despite the higher conversion efficiency in the GCM run than in the CSRM run prior to 00:00 LST on 17 July. Here, sub-cloud relative humidity does not play an important role in the presence and absence of precipitation in the GCM run and the CSRM run, respectively, since the time series of the relative humidity averaged over the sub-cloud layer in the CSRM run is similar to that in the GCM run; in general, the CSRM-run relative humidity is within $10 \%$ of the GCM-run relative humidity.

The presence of the surface precipitation in the GCM run throughout the entire simulation period stabilizes the whole sub-cloud layer as simulated in Lee et al. (2009), Jiang et al. (2002), and Feingold et al. (1996). The presence of surface precipitation in the GCM run implies that the effect of rain evaporation on the cloud-base instability would not be simulated even though the GCM adopted a resolution as high as that in the CSRM run. Lee et al. (2009) and Jiang et al. (2002) showed that when the precipitation reaches the surface, the instability effect was not active due to the stabilization of the whole sub-cloud layer. In other words, interactions between the supersaturation and CDNC play the most important role in the determination of the LWP in thin clouds in the case where precipitation reaches the surface as shown in Lee et al. (2009).

\section{Summary and conclusion}

A 20-day long-term simulation is performed using a CSRM coupled with a double-moment microphysics for a case of thin stratocumulus clouds located at $\left(30^{\circ} \mathrm{N}, 120^{\circ} \mathrm{W}\right)$ off the coast of the western Mexico. Initial conditions, large-scale forcings, and surface fluxes produced by a GCM simulation (the GCM run) at $\left(30^{\circ} \mathrm{N}, 120^{\circ} \mathrm{W}\right)$ are imposed on the CSRM simulation (the CSRM run), enabling a comparison of the simulated stratocumulus clouds by the CSRM to those by the GCM at $\left(30^{\circ} \mathrm{N}, 120^{\circ} \mathrm{W}\right)$. This comparison is used to examine how differently the CSRM with high resolutions and detailed representation of cloud microphysics simulates warm, thin marine stratiform clouds as compared to the GCM with its low resolution and heavily parameterized cloud microphysics.

Two cloud regimes are simulated in the CSRM run: stratocumulus (16:00 LST on 30 June-00:00 LST on 17 July) and cumulus (00:00 LST on 17 July-16:00 LST on 20 July) regimes. However, only stratocumulus clouds are simulated throughout the entire simulation period in the GCM run.

In the stratocumulus regime, the efficiency of the conversion of cloud liquid water to rain is very low in the CSRM run, leading to a negligible role of the conversion of cloud liquid water to rain and thus sedimentation as compared to condensation in the determination of the LWP in the CSRM run. The LWP is higher due to larger condensation in the GCM run than in the CSRM run for stratocumulus clouds. Also, it should be pointed out that the conversion of cloud liquid water to rain plays as important a role as condensation in the determination of the LWP in the GCM run. The lower condensation and conversion efficiency in the stratocumulus regime in the CSRM run leads to no precipitation reaching the surface. This prevents the stabilization of the whole subcloud layer and induces a local instability induced by rain evaporation around cloud base, which plays an important role in the determination of condensation and thus the LWP. In contrast, the high efficiency of the conversion of cloud liquid water to rain contributes to the presence of the surface precipitation in the GCM run. This stabilizes the whole sub-cloud layer and thus prevents the development of a local instability around cloud base. Also, the low resolution is not able to resolve interactions between the local instability around cloud base and the LWP in the GCM run. However, even though a resolution as high as that in the CSRM run were applied to the GCM run, the presence of surface precipitation implies that the local interactions between the instability and rain evaporation around cloud base would not be simulated in the GCM run. To confirm this, the CSRM run was repeated by adopting the microphysics parameterization from the GCM with no changes in the resolutions. We found, in this repeated simulation, precipitation reached the surface, which stabilized the entire sub-cloud layer and thus prevented the interactions between rain evaporation and cloud-base instability. Also, the CSRM run was repeated for each of Saleeby and Cotton's (2004) scheme and the microphysics scheme from the GCM with resolutions in the MBL as low as in the GCM. Comparisons in the results between these two CSRM runs showed that the CSRM with the GCM scheme produced the surface precipitation whereas the CSRM with Saleeby and Cotton's (2004) scheme produced no surface precipitation. This indicates that the presence of the surface precipitation is controlled by the choice of the microphysics scheme but not by the choice of resolutions.

In the CSRM run, the interactions between CDNC and supersaturation also play an important role in the determination of condensation and the LWP. Supersaturation produced by updrafts is consumed by condensation of water vapor onto droplets and increasing (decreasing) CDNC 
provides increasing (decreasing) surface areas of droplets for condensation, leading to decreasing (increasing) equilibrium supersaturation. These interactions are explicitly simulated in the CSRM run while condensation is diagnosed based on environmental conditions in the GCM run, in a manner similar to saturation adjustment (Zhang et al., 2003). It is found that the explicit simulation of these interactions (between $\mathrm{CDNC}$ and supersaturation and between rain evaporation and cloud-base instability) tends to produce less condensation in the CSRM run as compared to the scheme similar to saturation adjustment in the GCM run in the stratocumulus regime. Also, those interactions lead to a closer CSRM-run LWP to the MODIS-observed LWP than that in the GCM-run LWP in the stratocumulus regime.

In the cumulus regime, deepening-warming decoupling caused by the increasing surface latent heat fluxes leads to the development of cumulus clouds in the CSRM run. This contributes to a better agreement with the LWP between the CSRM run and the MODIS observation and to larger discrepancies in the radiation budget between the CSRM run and the GCM run. As shown in BW97, an increasing latent heat flux can lead to increasing negative buoyancy fluxes below the cloud base as well as to increasing positive fluxes in the cloud layer, which generates the conditional instability. This causes deepening-warming decoupling, inducing the development of cumulus clouds which are persistent during the daytime as well as the nighttime, which is different from diurnal decoupling where clouds go through a daytime dissipation and the nighttime development. In the GCM run where the interactions between the latent heat fluxes and buoyancy fluxes were not represented explicitly, the deepening-warming decoupling was not simulated. As stated in BW97, the simulation of deepening-warming decoupling in climate models requires the integration of a cumulus parameterization, a cloud microphysics parameterization, and a turbulence parameterization that accurately represents layer cloud feedbacks on boundary turbulence. This integrated parameterization should be able to predict the development of the conditional instability based on the magnitude of surface $\mathrm{LH}$ fluxes.

Also, it should be pointed out that the diurnal dissipation and development of stratocumulus clouds in the GCM run are not as clear as in the CSRM simulation (see Fig. 7a and b). We believe that this is mainly because of the absence of an explicit representation of interactions between the shortwave heating and the buoyancy fluxes in the GCM run.

The diurnal variation of LWP in the GCM run is much larger than that in the CSRM run. This leads to much larger temporal fluctuation in LWP in the GCM run than in the CSRM run as shown in Fig. 8a. It indicates that the saturation adjustment scheme in the GCM is much more sensitive to diurnal decoupling and thus the diurnal variation of the transportation of water vapor from the surface to the upper layers than the scheme predicting supersaturation in the CSRM. This demonstrates that the presence of interactions between
CDNC and supersaturation acts to damp down the variation in supersaturation with varying decoupling, whereas the absence of these interactions allows comparatively high supersaturation to occur. Further study to gain the understanding of the role of these interactions in supersaturation and sensitivity of clouds to diurnal decoupling is needed.

Increases in temperature around the Earth's surface due to increases in green house gases can increase the surface latent heat fluxes as indicated by BW97 who showed that surface latent heat fluxes increase with the increasing sea surface temperature. This implies that the deepening-warming decoupling can be affected by the climate changes associated with the increasing green house gases and thus the surface temperature. This may have impacts on the transition of stratocumulus clouds to cumulus clouds, in turn affecting the effects of warm clouds on the global radiation budget. As shown in this study, the GCM is not able to simulate this deepening-warming decoupling, and thus is expected to be unable to take into account the changing radiation budget due to possible changes associated with deepening-warming decoupling with increasing green house gases.

Interactions between CDNC and supersaturation and those between rain evaporation and cloud-base instability change with varying aerosols. This controls the LWP responses to aerosol changes in the thin, non-precipitating stratiform clouds as shown in the comparison between the CSRM run and the CSRM $\times 2$ run and as also reported in Lee et al. (2009). The role of autoconversion and collection processes and thus sedimentation in the LWP is negligible when spectral information in the size distribution is considered. However, the GCM is not capable of simulating those interactions and the spectral information, indicating that the GCM parameterization of shallow clouds is too limited and unable to simulate the changing aerosol-cloud interactions and their effects on thin stratocumulus clouds. Considering that thin stratocumulus clouds cover $28 \%$ of the globe and that a significant portion of these clouds has no surface precipitation (Turner et al., 2007), this limitation can be a considerable setback for the prediction of the responses of clouds to aerosol increases. Hence, microphysics parameterizations, able to predict particle mass and number, and thereby, surface area, coupled with a prediction of supersaturation, need to be implemented into climate models for a correct assessment of aerosol effects on thin stratocumulus clouds. Also, those parameterizations should be able to take into account the spectral information as well as rain evaporation and its effects on the instability around cloud base.

Current limitations on computational resources prevent the use of high resolution and short time steps in the GCM simulations, which are necessary for the simulation of the above-mentioned interactions associated with the cloud-base instability, the CDNC, and deepening-warming decoupling. In recent years, some GCMs have started to adopt very high resolutions, $\sim 4 \mathrm{~km}$ horizontally with similar vertical resolutions to those in the GCM used here (Miura et al., 
2007). However, these resolutions are still not high enough to resolve aerosol/cloud interactions in stratocumulus clouds. Thus, we have no choice but to parameterize those interactions at the current stage. The cloud-scale microphysical and dynamical developments are known to be sensitive not only to aerosol conditions but also to the environmental conditions in which clouds form as shown by the studies of Jiang et al. (2002), Ackerman et al. (2004), and Guo et al. (2007). Hence, these interactions are likely to be entangled with the environmental conditions such as the humidity, the largescale subsidence, the sea surface temperature, and the surface LH and SH fluxes (which were found to affect the cloud developments significantly in those studies) as well as aerosols. Hence, more case studies of thin stratiform clouds developing under the various environmental and aerosol conditions are needed to form a generalized basis for the development of better parameterizations.

This study assumed the gamma-size distribution for droplets. Although many observational studies have showed that droplets obey the gamma distribution, autoconversion and accretion may vary with the choice of the distribution. Additional tests using exponential and log-normal distributions showed that results here did not depend on the choice of the type of representative distributions of droplets generally used in modeling studies. However, evolution of dropsize distribution in this study was not simulated as explicitly as in bin-model studies. The effect of explicit simulation of droplets in each size bin with no assumed size distribution (as in bin-model studies) on the results here needs further investigation.

Acknowledgements. The authors wish to thank Wei-Kuo Tao and Derek Posselt for providing GCE coupled with double-moment microphysics used here and valuable discussions. This paper was prepared under US Department of Energy ARM program (DE FG02 97 ER62370).

Edited by: R. von Glasow

\section{References}

Andres, R. J. and Kasgnoc, A. D.: A time-averaged inventory of subaerial volcanic sulfur emissions, J. Geophys. Res., 103, 25251-25261, 1998.

Abdul-Razzak, H. and Ghan, S. J.: A parameterization of aerosol activation 2, Multiple aerosol types, J. Geophys. Res., 105, 6837-6844, 2000.

Abdul-Razzak, H. and Ghan, S. J.: A parameterization of aerosol activation - 3. Sectional representation, J. Geophys. Res., 107, 4026, doi:10.1029/2001JD000483, 2002.

Albrecht, B. A.: Aerosols, cloud microphysics, and fractional cloudiness, Science, 245, 1227-1230, 1989.

Beheng, K. D.: A parameterization of warm cloud microphysical conversion processes, Atmos. Res., 33, 193-206, 1994.

Bony, S. and Dufresne, J.-L.: Marine boundary layer clouds at the heart of tropical cloud feedback uncertainties in climate models,
Geophys. Res. Lett., 32, L20806, doi:10.1029/2005GL023851, 2005

Boville, B. A., Rasch, P. J., Hack, J. J., and McCaa, J. R.: Representation of clouds and precipitation processes in the community atmosphere model version 3 (cam3), J. Climate, 19, 2184-2198, 2006.

Boucher, O. and Lohmann, U.: The sulfate-CCN-cloud albedo effect, A sensitivity study with two general circulation models, Tellus, 47B, 281-300., 1995.

Bretherton, C. S. and Wyant, M. C.: Moisture transport, lowertropospheric stability, and decoupling of cloud-topped boundary layers, J. Atmos. Sci., 54, 148-167, 1997.

Chou, M.-D. and Kouvaris, L.: Calculations of transmission functions in the IR $\mathrm{CO}_{2}$ and $\mathrm{O}_{3}$ bands, J. Geophys. Res., 96, 90039012, 1991.

Chou, M.-D. and Suarez, M. J.: A shortwave radiation parameterization for atmospheric studies, 15, NASA/TM-104606, pp 40, 1999.

Chou, M.-D., Ridgway, W., and Yan, M.-H.: Parameterizations for water vapor IR radiative transfer in both the middle and lower atmospheres, J. Atmos. Sci., 52, 1159-1167, 1999.

Chuang, C. C., Penner, J. E., Taylor, K. E., Grossman, A. S., and Walton, J. J.: An assessment of the radiative effects of anthropogenic sulfate, J. Geophys. Res., 102, 3761-3778, 1997.

Collins, W. D., Rasch, P. J., Boville, B. A., Hack, J. J., McCaa, J. R., Williamson, D. L., Briegleb, B. P., Bitz, C. M., Lin, S. J., and Zhang, M. H.: The formulation and atmospheric simulation of the community atmosphere model version 3 (cam3), J. Climate, 19, 2144-2161, 2006.

Cotton, W. R., Stephens, M. A., Nehrkorn, T., and Tripoli, G. J.: The Colorado State University three-dimensional cloud/mesoscale model, Part II: An ice phase parameterization, J. Rech. Atmos. 16, 295-319, 1982.

Cubasch, U., Dai, X., Ding, Y., et al.: Climate change 2001: The scientific basis, in Contribution of Working Group I to the Third Assessment Report of the Intergovernmental Panel on Climate Change, Cambridge Univ. Press, New York, pp. 528-582, 2001.

Davis, A., Marshak, A., Wiscombe, W., and Cahalan, R. F.: Scale invariance of liquid water distribution in marine stratocumulus, Part I: Spectral properties and stationary issues, J. Atmos. Sci., 53, 1538-1558, 1996.

de la Torre Juárez, M., Kahn, B. H., and Fetzer, E. J.: Cloud-type dependencies of MODIS and AMSR-E liquid water path differences, Atmos. Chem. Phys. Discuss., 9, 3367-3399, 2009, http://www.atmos-chem-phys-discuss.net/9/3367/2009/.

de Roode, S. R., Duynkerke, P. G., and Jonker, H. J. J.: Large-eddy simulation: How large is large Enough?, J. Atmos. Sci., 61, 403421, 2004.

Donner, L. J., Seman, C. J., and Hemler, R. S.: Three-dimensional cloud-system modeling of GATE convection, J. Atmos. Sci., 56, 1885-1912, 1999.

Durand, P., Thoumieux, F., and Lambert, D.: Turbulent length scales in the marine atmospheric mixed layer, Q. J. Roy. Meteorol. Soc., 126, 1889-1912, 2000.

Feingold, G., Cotton, W., Kreidenweis, S., and Davis, J.: The impact of giant cloud condensation nuclei on drizzle formation in stratocumulus: Implications for cloud radiative properties, J. Atmos. Sci., 56, 4100-4117, 1999.

Feingold, G., Stevens, B., Cotton, W. R., and Frisch, A. S.: The 
relationship between drop in-cloud residence time and drizzle production in numerically simulated stratocumulus clouds, J. Atmos. Sci., 53, 1108-1122, 1996.

Feingold, G., Tzivion, S., and Levin, Z.: Evolution of raindrop spectra, Part I: Solution to the stochastic collection/breakup equation using the method of moments, J. Atmos. Sci., 45, 3387-3399, 1988.

Forster, P., Ramaswamy, V., Artaxo, P., et al.: Changes in atmospheric constituents and in radiative forcing, in: Climate change 2007: the physical science basis, Contribution of working group I to the Fourth Assessment Report of the Intergovernmental Panel on Climate Change, edited by: Solomon, S., Qin, D., Manning, M., et al., Cambridge Univ. Press, New York, 2007.

Ghan, S., Laulainen, N., Easter, R., Wagener, R., Nemesure, S., Chapman, E., Zhang, Y., and Leung, R.: Evaluation of aerosol direct radiative forcing in mirage, J. Geophys. Res., 106, 52955316, 2001.

Ginoux, P., Chin, M., Tegen, I., Prospero, J. M., Holben, B., Dubovik, O., and Lin, S. J.: Sources and distributions of dust aerosols simulated with the gocart model, J. Geophys. Res., 106, 20255-20273, 2001.

Grabowski, W. W., Wu, X., Moncrieff, M. W.: Cloud resolving modeling of tropical cloud systems during phase III of GATE, Part I: Two-Dimensional Experiments, J. Atmos. Sci., 53, 36843709, 1996.

Gong, S. L., Barrie, L. A., and Blanchet, J. P.: Modeling sea-salt aerosols in the atmosphere, 1. Model development, J. Geophys. Res., 102, 3805-3818, 1997.

Guo, H., Penner, J. E., Herzog, M., and Xie, S.: Investigation of the first and second aerosol indirect effects using data from the May 2003 Intensive Operational Period at the Southern Great Plains, J. Geophys. Res., 112, D15206, doi:10.1029/2006JD007173, 2007.

Hall, W.: A detailed microphysical model within a two-dimensional dynamic framework: Model description and preliminary results, J. Atmos. Sci., 37, 2486-2507, 1980.

Hartmann, D. L., Ockert-Bell, M. E., and Michelsen, M. L.: The effect of cloud type on the earth's energy balance, J. Climate, 5, 1281-1304, 1992.

Herzog, M., Weisenstein, D. K., and Penner, J. E.: A dynamic aerosol module for global chemical transport models: Model description, J. Geophys. Res., 109, D18202, doi:10.1029/2003jd004405, 2004.

Ito, A. and Penner, J. E.: Historical emissions of carbonaceous aerosols from biomass and fossil fuel burning for the period 1870-2000, Global Biogeochem. Cy., 19, GB2028, doi:10.1029/2004GB002374, 2005.

Jiang, H., Feingold, G., and Cotton, W. R.: Simulations of aerosol-cloud-dynamical feedbacks resulting from entrainment of aerosol into the marine boundary layer during the Atlantic Stratocumulus Transition Experiment, J. Geophys. Res., 107, 4813, doi:10.1029/2001JD001502, 2002.

Jonker, H. J. J., Duynkerke, P. G., and Cuijpers, J. W. M.: Energy spectra in the mesoscale range: An LES study. Preprints, 12th Symp. on Boundary Layers and Turbulence, Vancouver, BC, Canada, B. Am. Meteorol. Soc., 225-226, 1997.

Kettle, A. J. and Andreae, M. O.: Flux of dimethylsulfide from the oceans: A comparison of updated data seas and flux models, J. Geophys. Res., 105, 26793-26808, 2000.
Klemp, J. B. and Wilhelmson, R.: The simulation of three-dimensional convective storm dynamics, J. Atmos. Sci., 35, 1070-1096, 1978.

Kratz, D. P., Chou, M.-D., Yan, M.-H., and Ho, C.-H.: Minor trace gas radiative forcing calculations using the k-distribution method with one-parameter scaling, J. Geophys. Res., 103, 3164731656, 1998.

Krueger, S. K., Cederwall, R. T., Xie, S. C., and Yio, J. J.: GCSS Working Group for Model Intercomparison - Procedures for Case 3: Summer 1997 ARM SCM IOP, Technical report obtainable from http://www.arm.gov/docs/scm/scmic3, 1999.

Lee, S. S, Penner, J. E., and Saleeby, S. M.: Aerosol effects on liquid-water path of thin stratocumulus clouds, J. Geophys. Res., 114, D07204, doi:10.1029/2008JD010513, 2009.

Liu, X., Penner, J. E., and Herzog, M.: Global modeling of aerosol dynamics: Model description, evaluation, and interactions between sulfate and nonsulfate aerosols, J. Geophys. Res., 110, D18206, doi:10.1029/2004JD005674, 2005.

Liu, X., Penner, J. E., and Wang, M.: Influence of anthropogenic sulfate and black carbon on upper tropospheric clouds in the NCAR CAM3 model coupled to the IMPACT global aerosol model, J. Geophys. Res., 114, D03204, doi:10.1029/2008JD010492, 2009.

Long, A.: Solutions to the droplet collection equation for polynomial kernels, J. Atmos. Sci., 31, 1040-1052, 1974.

Miura, H., Satoh, M., Nasuno, T., Noda, A. T., and Oouchi, K.: A Madden-Julian oscillation event realistically simulated by a global cloud-resolving model, Science, 318, 1763-1765, 2007.

Nicholls, S. and LeMone, M. A.: 1980: The fair weather boundary layer in GATE: The relation of subcloud fluxes and structure to the distribution and enhancement of cumulus clouds, J. Atmos. Sci., 37, 2051-2067, 1980.

Nucciarone, J. J. and Young, G. S.: Aircraft measurements of turbulence spectra in the marine stratocumulus-topped boundary layer, J. Atmos. Sci., 48, 2382-2392, 1991.

Paluch, I. R. and Lenschow, D. H.: Stratiform cloud formation in the marine boundary layer, J. Atmos. Sci., 48, 2141-2158, 1991.

Penner, J. E., Andreae, M., Annegarn, H., Barrie, L., Feichter, J., Hegg, D., Jayaraman, A., Leaitch, R., Murphy, D., Nganga, J., and Pitari, G.: Aerosols, their Direct and Indirect Effects, in: Climate Change 2001: The Scientific Basis, edited by: Houghton, J. T., Ding, Y., Griggs, D. J., Noguer, M., Van der Linden, P. J., Dai, X., Maskell, K., and Johnson, C. A., Report to Intergovernmental Panel on Climate Change from the Scientific Assessment Working Group (WGI), Cambridge University Press, 289-416, 2001.

Pruppacher, H. R. and Klett, J. D.: Microphysics of Clouds and Precipitation, D. Reidel, 714pp, 1978.

Ramaswamy, V., Boucher, O., Haigh, J., et al.: Radiative forcing of climate change, in: Climate Change 2001: The Scientific Basis, edited by: Houghton, J. T., Ding, Y., Griggs, D. J., et al., Cambridge Univ. Press, New York, 349-416, 2001.

Rasch, P. J. and Kristjánsson, J. E.: A comparison of the CCM3 model climate using diagnosed and predicted condensate parameterizations, J. Climate, 11, 1587-1614, 1998.

Rogers, R. R. and Yau, M. K.: A short course in cloud physics, Pergamon Press, 293pp, 1991.

Rothermel, J. and Agee, E. M.: Aircraft investigation of mesoscale cellular convection during AMTEX 75, J. Atmos. Sci., 37, 1027 
1049, 1980.

Saleeby, S. M. and Cotton, W. R.: A large-droplet mode and prognostic number concentration of cloud droplets in the Colorado state university regional atmospheric modeling system (RAMS), Part I: Module description and supercell test simulations, J. Appl. Meteorol., 43, 182-195, 2004.

Simpson, J. and Tao, W.-K.: The Goddard Cumulus Ensemble model, Part II: Applications for studying cloud precipitating processes and for NASA TRMM, Terr. Atmos. Ocean. Sci., 4, 73116, 1993.

Smith, S. J., Pitcher, H., and Wigley, T. M. L.: Global and regional anthropogenic sulfur dioxide emissions, Global Planet. Change, 29, 99-119, 2001.

Smith, S., Andres, R., Conception, L., and Lurz, J.: Historical sulfur dioxide emissions 1850-2000: Methods and resutls, jgcri research report pnnl 14537, Paciific Northwest National Laboratory, Richland, WA, USA, 14537, 16, 2004.

Soong, S.-T. and Ogura, Y.: Response of trade wind cumuli to largescale processes, J. Atmos. Sci., 37, 2035-2050, 1980.

Tao, W.-K., Simpson, J., Baker, D., et al.: Microphysics, radiation and surface processes in the Goddard Cumulus Ensemble (GCE) model, Meteorol. Atmos. Phys., 82, 97-137, 2003.

Tao, W.-K. and Simpson, J.: The Goddard Cumulus Ensemble model, Part I: Model description, Terr. Atmos. Ocean. Sci., 4, 19-54, 1993.

Textor, C., Schulz, M., Guibert, S., Kinne, S., Balkanski, Y., Bauer, S., Berntsen, T., Berglen, T., Boucher, O., Chin, M., Dentener, F., Diehl, T., Easter, R., Feichter, H., Fillmore, D., Ghan, S., Ginoux, P., Gong, S., Grini, A., Hendricks, J., Horowitz, L., Huang, P., Isaksen, I., Iversen, I., Kloster, S., Koch, D., Kirkevåg, A., Kristjansson, J. E., Krol, M., Lauer, A., Lamarque, J. F., Liu, X., Montanaro, V., Myhre, G., Penner, J., Pitari, G., Reddy, S., Seland, Ø., Stier, P., Takemura, T., and Tie, X.: Analysis and quantification of the diversities of aerosol life cycles within AeroCom, Atmos. Chem. Phys., 6, 1777-1813, 2006, http://www.atmos-chem-phys.net/6/1777/2006/.

Tiedtke, M., Heckley, W. A., and Slingo, J.: Tropical forecasting at ECMWF: The influence of physical parameterization on the mean structure of forecasts and analyses, Q. J. Roy. Meteorol. Soc., 114, 639-644, 1988.
Tompkins, A. M. and Craig, G. C.: Radiative-convective equilibrium in a three-dimensional cloud ensemble model, Q. J. Roy. Meteorol. Soc., 124, 2073-2098, 1998.

Tripoli, G. J. and Cotton, W. R.: A numerical investigation of several factors contributing to the observed variable intensity of deep convection over South Florida, J. Appl. Meteorol., 19, 10371063, 1980.

Turner, D. D., Vogelmann, A. M., Austin, R. T., et al.: Thin liquid water clouds: Their importance and our challenge, B. Am. Meteorol. Soc., 88, 177-190, 2007.

Twomey, S.: The influence of pollution on the shortwave albedo of clouds, J. Atmos. Sci., 34, 1149-1152, 1977.

Twomey, S.: Computations of rain formation by coalescence, J. Atmos. Sci., 23, 405-411, 1966.

Wang, M., Penner, J. E., and Liu, X.: Coupled IMPACT aerosol and NCAR CAM3 model: Evaluation of predicted aerosol number and size distribution, J. Geophys. Res., 114, D06302, doi:10.1029/2008JD010459, 2009.

Wang, M. and Penner, J. E.: Aerosol indirect forcing in a global model with particle nucleation, Atmos. Chem. Phys., 9, 239-260, 2009 , http://www.atmos-chem-phys.net/9/239/2009/.

Walko, R. L., Cotton, W. R., Meyers, M. P., and Harrington, J. Y.: New RAMS cloud microphysics parameterization: Part I, The single-moment scheme, Atmos. Res., 38, 29-62, 1995.

Whitby, K. T.: The physical characteristics of sulfur aerosols, Atmos. Environ., 12, 135-159, 1978.

Xiping, Z., Kumar, S., Eastman, J. L., et al.: Evaluating clouds in long-term cloud-resolving model simulations with observational data, J. Atmos. Sci., 64, 4153-4177, 2007.

Xu, K.-M., Cederwall, R. T., Donner, L. J., et al.: An intercomparison of cloud-resolving models with the Atmospheric Radiation Measurement summer 1997 Intensive Observation Period data, Q. J. Roy. Meteorol. Soc., 128, 593-624, 2002.

Young, G. S.: Mixed layer spectra from aircraft measurements, J. Atmos. Sci., 44, 1251-1256, 1987.

Zhang, M., Lin, W., Bretherton, C. S., Hack, J. J., and Phillip, J. R.: A modified formulation of fractional stratiform condensation rate in the NCAR Community Atmospheric Model (CAM2), J. Geophys. Res., 108, 4035, doi:10.1029/2002JD002523, 2003. 